\title{
Flexible Shear Mode Transducer for Structural Health Monitoring Using Ultrasonic Guided Waves
}

\author{
Premesh S. Lowe, Member, IEEE, Timo Scholehwar, Jimmy Yau, Jamil Kanfoud, Tat-Hean Gan, \\ and Cem Selcuk
}

\begin{abstract}
The application of the fundamental shearhorizontal wave mode for guided wave structural health monitoring is undoubtedly beneficial due to its nondispersive characteristics. Existing guided wave shear mode transducers are rigid and brittle, because of these characteristics, bonding them to irregular surfaces (i.e., curved surfaces) is challenging. There is a huge market interest in the development of a flexible shear mode transducer, which eases the transducer bonding process onto irregular surfaces and improves the surface contact between the transducer and the structure. This study presents a flexible shear mode transducer for structural health monitoring using low-frequency guided waves (20-120 kHz). The proposed transducer is manufactured using piezoceramic, and based on the results of this study, it exhibits the directional excitation of fundamental shear-horizontal mode at $20-120 \mathrm{kHz}$. Finite element analysis and laboratory experiments were conducted to study the behavior of the proposed transducer. Field trials were conducted on a liquid storage tank with an undulated surface (due to corrosion). The performance of the proposed transducer is also compared to the commercially available macro fiber composite transducers. The proposed transducer was driven by the industrialized ultrasonic guided wave inspection system; Teletest Focus + in line with the application of tank floor inspection using ultrasonic guided waves.
\end{abstract}

Index Terms-Directionality, flexibility, industrialization, shear mode transducer, structural health monitoring (SHM), ultrasonic guided wave (UGW). TRUCTURAL health monitoring (SHM) of degrading engineering structures due to various factors (such as corrosion) is important as degradation could lead to structural

Manuscript received August 5, 2017; revised September 14, 2017 , October 23, 2017, and November 2, 2017; accepted November 12, 2017. Paper no. TII-17-1775. (Corresponding author: Premesh S. Lowe.)

P. S. Lowe, J. Yau, J. Kanfoud, and T.-H. Gan are with Brunel University London, Uxbridge UB8 3PH, U.K. (e-mail: shehan.lowe@brunel.ac.uk; jimmy.yau@brunel.ac.uk; jamil.kanfoud@brunel.ac.uk; tat-hean.gan@ brunel.ac.uk).

T. Scholehwar is with PI Ceramic $\mathrm{GmbH}$, Lindenstrasse 07589, Germany (e-mail: t.scholehwar@piceramic.de).

C. Selcuk is with The Welding Institute Ltd., Great Abington CB21 6AL, U.K. (e-mail: cem.selcuk@twi.co.uk).

Color versions of one or more of the figures in this paper are available online at http://ieeexplore.ieee.org.

Digital Object Identifier 10.1109/TII.2017.2775343 instability causing harm to the industry and the environment Low-frequency $(20-120 \mathrm{kHz})$ ultrasonic guided waves (UGWs) are widely used to inspect the structural health of elongated structures (i.e., pipes, plates, rails, cables) due to their inherent feature of long-range propagation [1]. Commercial UGW systems have evolved vastly over two decades to fulfill industry requirements. The development of UGW transducers is a core aspect with great interest, particularly for the inspection of complex structures (such as floor of liquid storage tanks). Early research on transducer development for commercial UGW systems has been conducted by Alleyne and Cawley, where they developed a transducer with thickness-shear motion to excite Lamb waves on a plate [2]. The development of flexible transducers for UGW application became imperative since early 2000 with the interest of inspecting structures with curved and/or irregular surfaces [3], [4].

Piezoelectric films (polyvinylidene fluoride, PVDF) is one of the earliest flexible transducers for UGW application [5]. PVDF transducers are flexible and durable. Compared to lead zirconate titanate (PZT), PVDF requires higher actuation power and heavy amplification. PVDFs work better in a higher frequency range (0.5-4 MHz) [5], and this limits the long-range propagation capabilities of UGW due to the typically higher attenuation rates at these frequencies. Another transducer was developed by combining the electromechanical efficiency of PZT with mechanical flexibility. Examples of these are active fiber composite (AFC) and macro fiber composite (MFC) [3]. AFC and MFC are thin piezoceramic fibers that are aligned unidirectionally and exploit the use of interdigitated electrodes, which deliver a stronger longitudinal piezoelectric effect along the length of fibers [4]. This is performed by applying an electric field in the direction of fiber axis, which in turn generates a stronger longitudinal $\left(d_{33}\right.$ constant) piezoelectric effect. AFCs operate in low hundreds of $\mathrm{kHz}$ range [6] and $\mathrm{MFCs}$ operate in tens of $\mathrm{kHz}$ to $\mathrm{MHz}$ range [7], [8]. The main advantage of MFCs in comparison to AFCs and PVDFs is the reduced manufacturing cost. MFCs are mass manufactured and distributed by Smart Material Corp. [9].

The patch transducer is a piezoceramic-based flexible transducer (commercial name-DuraAct), which was designed by German Aerospace Centre and is manufactured and distributed by PI Ceramic (PIC) GmbH [10]. The DuraAct transducer operates in $\mathrm{kHz}$ to $\mathrm{MHz}$ range depending on the application requirement [11]. DuraAct transducers were initially used to detect the 
impact of a tail boom structure in 2010 using guided waves [12]. Since then, DuraAct transducers are used for many applications using UGWs in different frequency ranges. DuraAct transducers have gained a higher interest in the Aerospace industry to inspect composite materials [13], [14]. Compared to other flexible transducers, DuraAct transducers have proven to survive under harsh environmental conditions [15]. Standard MFCs cannot operate beyond $80^{\circ} \mathrm{C}$, whereas DuraAct can operate up to $150-200^{\circ} \mathrm{C}$, though the mechanical flexibility is limited at these temperatures. Lifespan of piezoceramic patch transducers was investigated in 2007 [16]. A key parameter investigated in this study was the flexibility of piezoceramic patch transducers by studying the performance of the transducer under tensile stress. As an outcome, minimum bending radius $\left(r_{\min }\right)$ can be calculated as follows and it depends on the ceramic thickness:

$$
r_{\min }=8 . e^{t .4 .4}
$$

where $e$ is the Euler constant, and $t$ is the thickness of the ceramic layer in $\mathrm{mm}$.

Common features of the aforementioned flexible transducers (PVDF, AFC, MFC, and DuraAct) are flexibility, lightweight [17], and more importantly, these transducers predominantly excite Lamb modes [18]. According to the literature, research on flexible transducer development was limited to excite Lamb modes [18], [19] or they operate at a higher frequency range (above $0.5 \mathrm{MHz}$ [20]-[22].

As stated in the literature, the most preferable UGW mode for the inspection of liquid storage tank floors is the fundamental shear-horizontal wave mode due to the relatively low attenuation and dispersion rates [1], [23]. Based on surface irregularities caused by the corrosion, transducers have to be flexible and cannot be rigid and/or brittle for this application. Currently, commercially available MFC transducers are used to obtain a better surface contact compared to rigid transducers [9]. However, based on directionality patterns of the MFC transducer, only the fundamental symmetric Lamb mode can be used for inspection, as the fundamental shear mode is excited in the diagonal direction, which complicates the signal processing [24]. The MFC transducer generates both fundamental Lamb modes in one direction, which complicates the signal interpretation. There is a higher market interest in the development of a flexible transducer, which generates the fundamental shear-horizontal mode perpendicular to the axis of vibration. According to author's knowledge, no attention has been given to develop a flexible transducer, which predominantly excites shear modes with directionality at low-frequency range $(20-120 \mathrm{kHz})$.

This study presents a flexible transducer, which generates the fundamental shear-horizontal mode perpendicular to the axis of vibration. The frequency range of interest is $20-120 \mathrm{kHz}$ due to the long-range propagation capabilities of UGWs for SHM [1]. The behavior of the proposed transducer was studied using numerical simulations, and laboratory experiments were conducted to validate the numerical results. Proposed transducers were also installed onto a liquid storage tank with an undulated surface (due to corrosion) to study the performance over a range of frequencies. Commercially available Teletest Focus +
UGW system [25] was used to excite the transducer during both laboratory and field trials.

This paper is organized as follows. Numerical simulations are presented in Section II, and the manufacturing process of the proposed flexible shear mode (FSM) transducer is reported in Section III. Laboratory experiments and field trial results are documented in Section IV. Section V presents the performance review of the proposed transducer, followed by the conclusions in Section VI.

\section{NUMERICAL SimULATION}

\section{A. Finite Element Analysis (FEA)}

Finite element analysis (FEA) has been performed to study the wave propagation behavior (directionality) of the proposed FSM transducer. With increased complexity of the analysis, analytical calculations are no longer practical [26]. A three-dimensional (3-D) model was built to conduct the aforementioned numerical analysis using ABAQUS/ EXPLICIT version 6.13 [27]-[29]. A solid transient analysis was conducted, which is governed by Navier's equation of motion for an isotropic media as follows [1]:

$$
(\lambda+\mu) \nabla \nabla \cdot u+\mu \nabla^{2} u=\rho\left(\frac{\partial^{2} u}{\partial t^{2}}\right)
$$

where $\lambda$ and $\mu$ are Lamé constants, $u$ is the 3-D displacement vector, $\nabla^{2}$ is the 3-D Laplace operator, and $\rho$ is the material density. Unknown potentials governing the Lamb (3) and shear (4) modes can be extracted as follows by substituting the potentials of Helmholtz decomposition into (2):

$$
\begin{aligned}
& \left(\frac{\partial^{2} \emptyset}{\partial t^{2}}\right)=c_{l}^{2} \nabla^{2} \emptyset \\
& \left(\frac{\partial^{2} \Phi}{\partial t^{2}}\right)=c_{s}^{2} \nabla^{2} \Phi
\end{aligned}
$$

where $\emptyset$ is the compressional scalar potential, $\Phi$ is the equivoluminal vector potential, and $c_{l}$ and $c_{s}$ are the velocities of Lamb and shear modes, respectively.

A circular plate was modeled with a $0.4 \mathrm{~m}$ radius and a thickness of $6.25 \mathrm{~mm}$. Dispersion curves for a $6.25 \mathrm{~mm}$ thick steel plate are illustrated in Fig. 1. Dispersion curves are plotted using the commercially available software DISPERSE [30]. The dispersion curve diagram illustrates the velocity of mode in relation to the frequency with separate curves for each existing mode in a frequency range. Based on the geometry and the operating frequency range of the current study, excitable modes are fundamental symmetric Lamb mode S0, asymmetric Lamb mode A0, and shear-horizontal mode SHO. As illustrated in Fig. 1, SH0 is the only nondispersive mode in the UGW operating frequency range, which is of a great interest for UGW inspection [1]. The size of the active ceramic plate of the proposed FSM transducer is $25 \times 25 \times 0.2 \mathrm{~mm}^{3}$ (width, height, and thickness, respectively). The overall actuator size is $38 \times 30 \times$ $0.5 \mathrm{~mm}^{3}$ due to the necessary encapsulation and electrical contacts. Since the difference in volume is passive, it does not have a 

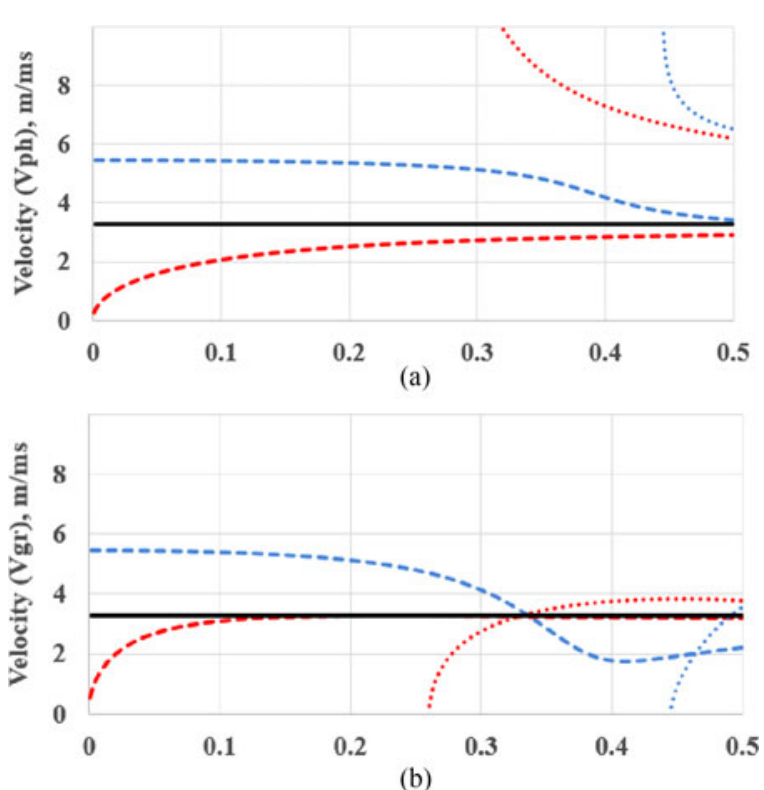

Frequency, $\mathbf{M H z}$

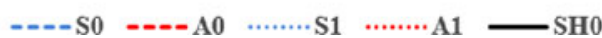

Fig. 1. Dispersion curves for a $6.25 \mathrm{~mm}$ thick steel plate: (a) phase velocity and (b) group velocity.

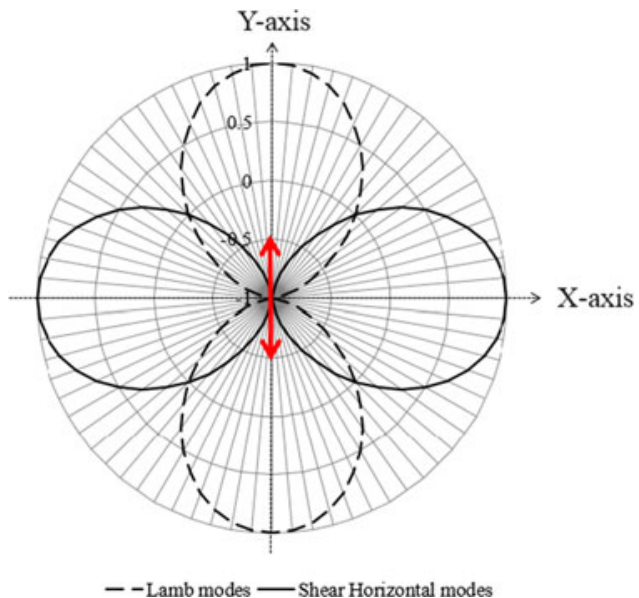

Fig. 2. Directivity pattern of the Lamb and shear-horizontal modes due to the surface shear vibration in the $y$-axis caused by a point source. The vertical axis represents the amplitude.

significant influence on the performance or symmetry of the waves generated.

Theoretical wave propagation directionality of a point source vibrating in-plane is illustrated in Fig. 2 [24]. Unlike Lamb modes, SH modes propagate perpendicular to the axis of vibration. As shown in Fig. 2, if the transducer vibrates in the $y$-axis, SH mode should propagate in both $x$-axis directions and Lamb modes should propagate in both $y$-axis directions [31]. Assumed material properties for the FEA are presented in Table I. The vibration mode of the modeled PIC 255 soft PZT [32] is the 1-5 thickness-shear mode.

Layout of the FE model is illustrated in Fig. 3. Transducer was bonded at the center of the plate using tie constraint to
TABLE I

Assumed Material Properties for the Numerical Simulation

\begin{tabular}{lcc}
\hline \hline Property & Steel & PIC 255 soft PZT \\
\hline Density $(\rho)$ & $7830 \mathrm{~kg} / \mathrm{m}^{3}$ & $7800 \mathrm{~kg} / \mathrm{m}^{3}$ \\
Young's modulus $(E)$ & $207 \mathrm{GPa}$ & $110 \mathrm{GPa}$ \\
Poisson's ratio $(v)$ & 0.3 & 0.36 \\
Piezoelectric charge $\left(d_{15}\right)$ & & $550 \cdot 1 \mathrm{e}-12 \mathrm{~m} / \mathrm{V}$ \\
Piezoelectric voltage $\left(g_{15}\right)$ & & $37 \cdot 1 \mathrm{e}-3 \mathrm{Vm} / \mathrm{N}$ \\
Coupling factor $\left(k_{15}\right)$ & & 0.66 \\
\hline
\end{tabular}

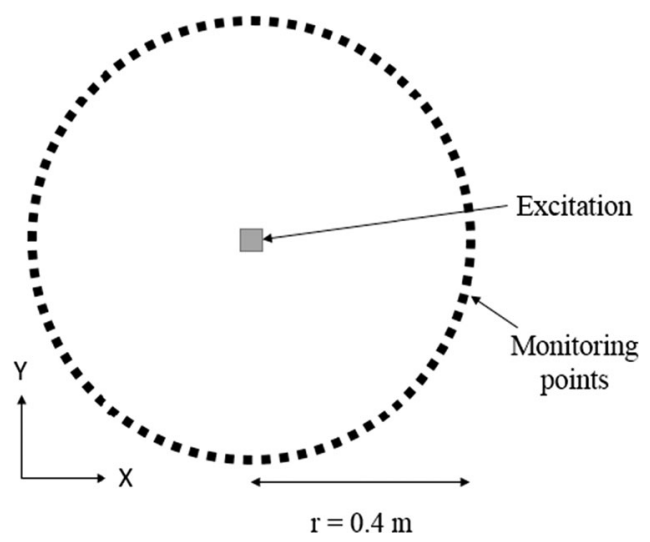

Fig. 3. Layout of the finite element model.

obtain a firm surface contact [27]. Size of mesh elements $\left(h_{o}\right) 194$ was in the range of $3.125-3.13 \mathrm{~mm}$ and calculated as follows: 195

$$
h_{o}=\frac{c}{N f_{o}}
$$

where $c$ is the velocity of the slowest mode, $N$ is the number 196 of elements per wavelength, and $f_{o}$ is the frequency of interest. 197 The linear eight node brick elements with reduced integration 198 (ABAQUS element type C3D8R) were used to achieve efficient 199 computation time, and the mesh refinement was such that there 200 were at least eight elements to represent the smallest possible 201 wavelength in the main lobe of the frequency bandwidth. This 202 level of mesh refinement has been validated in the previous stud- 203 ies [26], [33]. The excitation tone-burst was a $90 \mathrm{kHz} 5$-cycle 204 Hann-windowed pulse. This particular frequency and the num- 205 ber of cycles were chosen in order to individually identify modes 206 due to the length limitation of the modeled plate. Transmitted 207 signals were monitored $0.4 \mathrm{~m}$ away from the excitation.

\section{B. FEA Results}

Numerical results are illustrated in Figs. 4 and 5. Fig. 4 represents contour plots of propagated waves at different time increments and illustrates that the $\mathrm{SH} 0$ mode is predominantly excited in both $x$-axis directions according to the coordinates shown in Fig. 2. The polar plot in Fig. 5(a) validates the above-mentioned claim and matches with the theoretical wave propagation behavior of a shear mode transducer as reported in the literature (see Fig. 2). The time-domain data presented in Fig. 5(b) show that $\mathrm{SH} 0$ is the only propagated mode at $90^{\circ}$. This gives the confidence to use the proposed FSM transducer for the tank floor inspection using UGW due to the predominant and directional

\author{
95
} 6 97 8 99

in

.

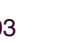

.

,

207




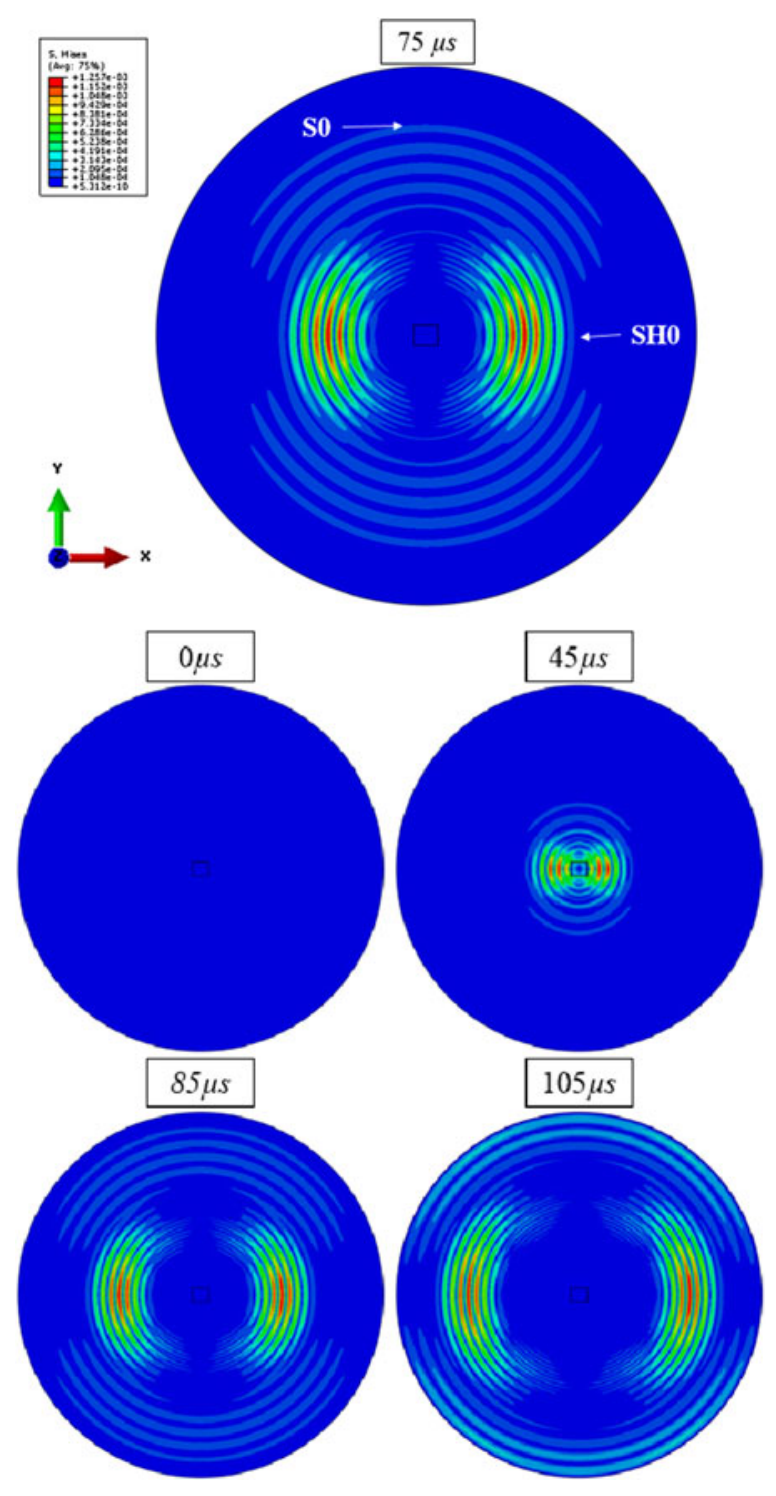

Fig. 4. FEA results; wave propagation at different time increments on a $0.4 \mathrm{~m}$ radius steel plate at $90 \mathrm{kHz}$ and the color scale represents the von-Mises stress. excitation of SH0. This is further investigated in Section IV-B and further discussed in Section V. The first mode to arrive is $\mathrm{SO}$, which is the fastest mode, and then SHO and A0. Time of arrival (ToA) of each mode is presented in Table II, and ToA can be calculated as follows:

$$
\mathrm{ToA}=\frac{x}{V_{\mathrm{gr}}}
$$

where $x$ is the distance of propagation, and $V_{\mathrm{gr}}$ is the group velocity of the mode of interest.

\section{MANufacturing Process of the PROPOSED TRANSDUCER}

The proposed FSM transducer has a similar manufacturing process in relation to the existing DuraAct transducers, which operates longitudinally (see Section I) [12]. Manufacturing process of the proposed transducer is as follows. The first step of

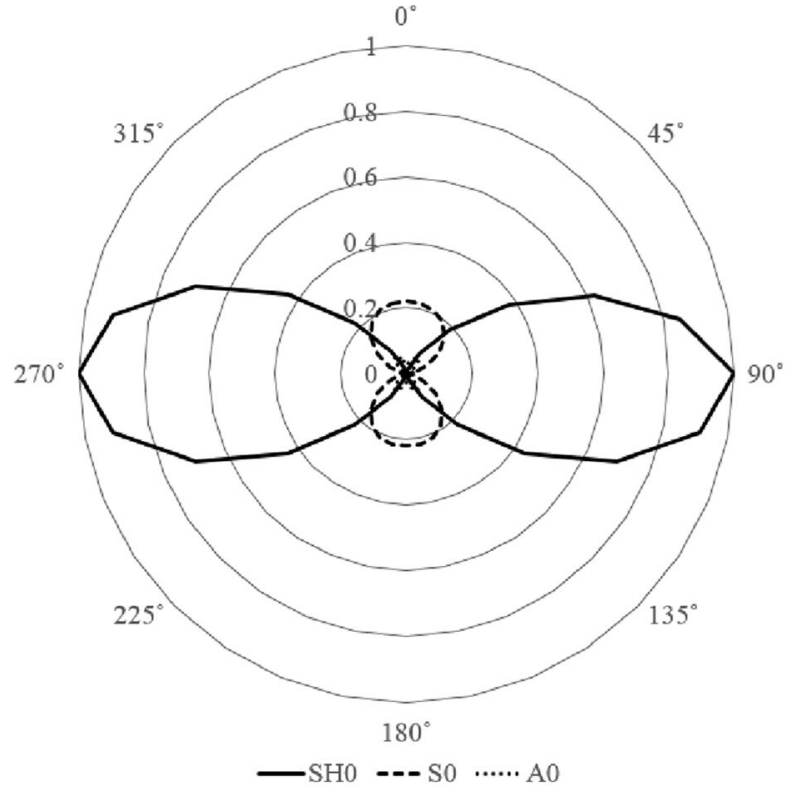

(a)

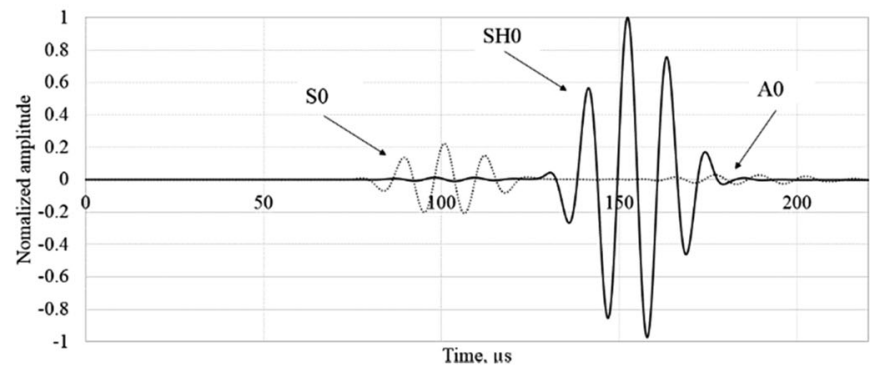

(b)

Fig. 5. Numerical modeling results at $90 \mathrm{kHz}$. (a) Polar plot illustrating the propagation directionality of the proposed shear transducer and the vertical axis represents the normalized amplitude and (b) time-domain data illustrating the monitored data at $0^{\circ}$ (dotted line) and $90^{\circ}$ (solid line).

TABLE II

Numerical Results-ToA of EACH Mode Monitored 0.4 M AWAY FROM THE POINT OF EXCITATION, WHICH CORRESPONDS TO THE INFORMATION SHOWN IN FIG. 5

\begin{tabular}{lcc}
\hline \hline Mode & $\begin{array}{c}\text { Velocity, } \\
V_{\mathrm{gr}}(\mathrm{m} / \mathrm{ms})\end{array}$ & $\begin{array}{c}\text { ToA } \\
(\mu \mathrm{s})\end{array}$ \\
\hline S0 & 5.4 & 74 \\
SH0 & 3.2 & 125 \\
A0 & 2.6 & 153 \\
\hline \hline
\end{tabular}

manufacturing the proposed FSM transducer is the production 234 of thickness-shear piezoceramic plates. The PZT material used 235 in the FSM transducer is PIC 255 soft PZT [32]. PZT blocks, 236 approximately in the dimensions of $40 \times 30 \times 25 \mathrm{~mm}^{3}$ are 237 polarized at $2,5-3,5 \mathrm{kV} / \mathrm{mm}$. Followed by cutting blocks into 238 plates at $0^{\circ}$ toward the polarization vector. The polarization is 239 in-plane and marked by a small notch, as illustrated in Fig. 6. 240 Then, electrodes are sputtered and plates are cut to final size 241 (dimensions of the active element are shown in Fig. 6). The 242 production process for these shear plates has to be carried out 243 in ambient temperature (i.e., significantly less than the Curie 244 

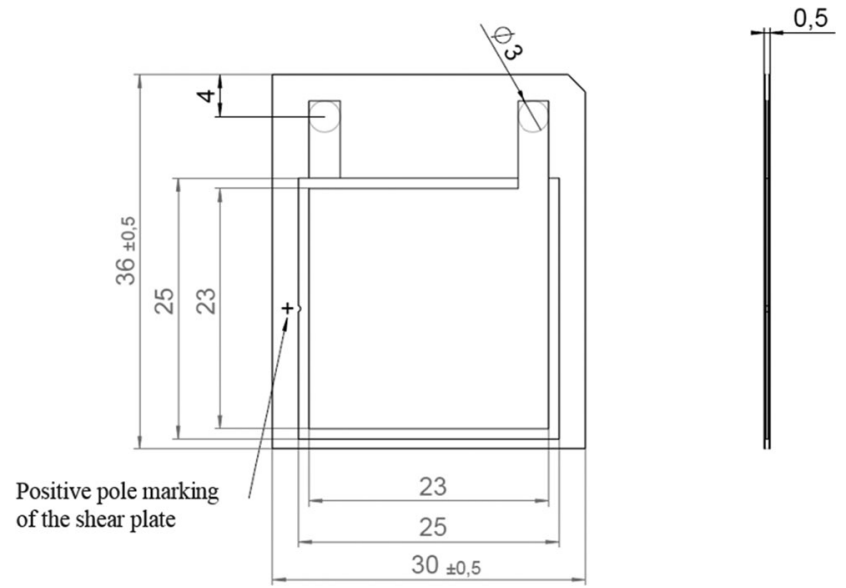

Fig. 6. Schematics of the proposed FSM transducer, dimensions are in $\mathrm{mm}$. Published courtesy of PI Ceramic $\mathrm{GmbH}$.

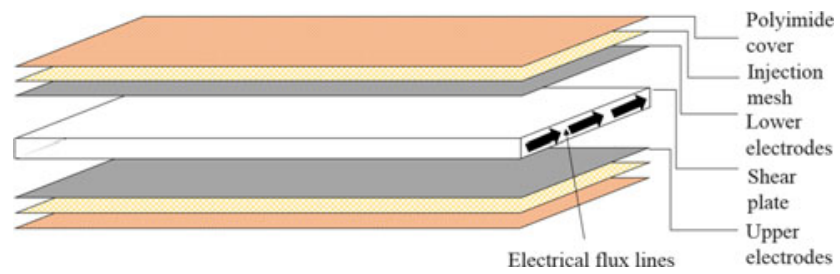

Fig. 7. Different layers in the proposed FSM transducer.

temperature). When an electrical signal is applied to the electrodes, the polarization vector of ferroelectric domains in the material is forced to turn toward the signal field, resulting in an opposite shear movement of electrode surfaces in the direction of the polarization field.

After completion of the production of shear plates, next step is the assembly process. Various layers of the proposed FSM transducer are dry-stacked in an autoclave as follows (see Fig. 7):

1) Polyimide prepreg cover,

2) Lower injection mesh (polyimide),

3) Lower collector electrodes,

4) Manufactured PZT shear plate and the positioning frame,

5) Upper collector electrodes and soldering pads,

6) Upper injection mesh, and

7) Polyimide prepreg cover.

This stack is then sealed on two sides. One open side is connected to a polyimide resin tank and the other is open to the autoclave's vacuum. Then, the autoclave is evacuated and heated up to $\sim 200^{\circ} \mathrm{C}$. The vacuum draws the resin through both injection mesh layers, which is followed by the resin curing. At the final step, transducers were laser-cut from the cured stack. Soldering pads were also uncovered during this process.

Curing of the transducer exerts a permanent lateral pressure of $44 \mathrm{MPa}$. This in return results in a much tighter potential bending radius because this inner stress has to be overcome before there is any actual negative stress in the surface of the ceramic. This will inherit the flexibility to the proposed transducer, which is an important characteristic in bonding transducers on to an irregular or curved surface. Thickness of the PZT element used in the proposed FSM transducer is $0.2 \mathrm{~mm}$ and

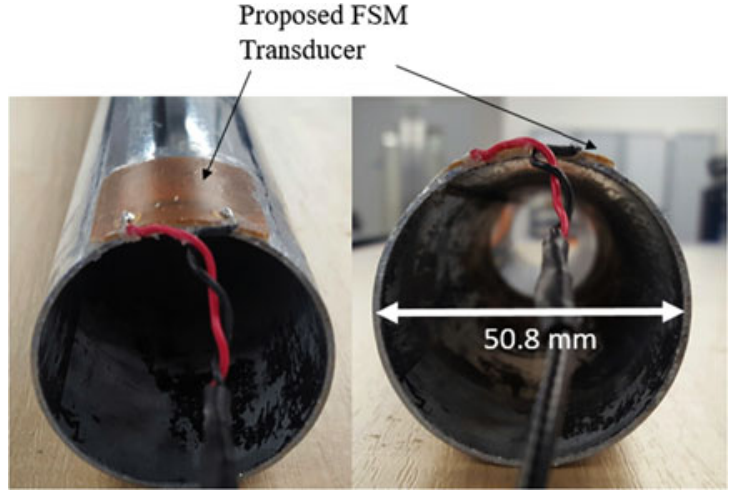

Fig. 8. Photograph of the proposed FSM transducer attached to a $50.8 \mathrm{~mm}$ diameter pipe to illustrate the flexibility of the transducer (illustrating $10 \mathrm{~mm}$ bending radius).

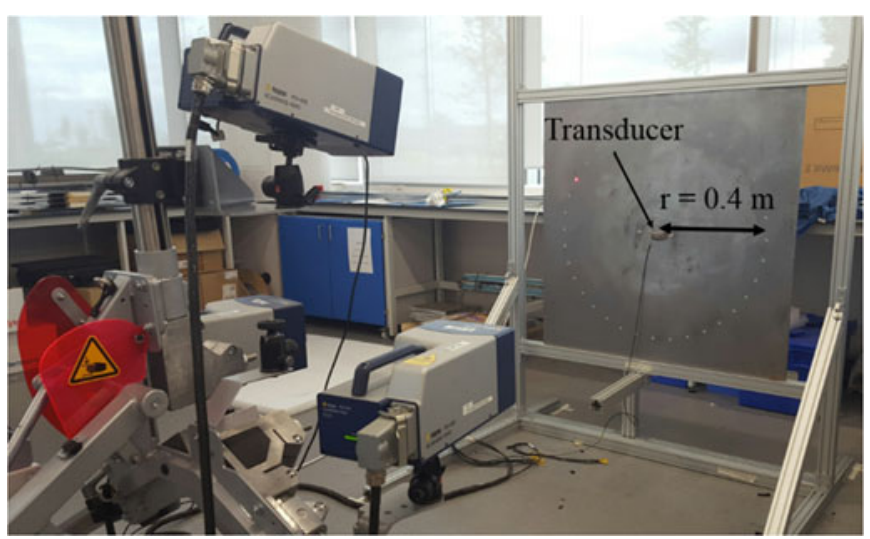

Fig. 9. Laboratory experimental setup.

according to (1), bending radius of the proposed FSM transducer is $20 \mathrm{~mm}$. Photographs of the proposed FSM transducer are shown in Fig. 8. The proposed FSM transducer is attached to the edge of a $50.8 \mathrm{~mm}$ diameter steel pipe using acrylic adhesive showing a $10 \mathrm{~mm}$ bending radius for illustration purposes.

\section{EXPERIMENTAL VALIDATION}

\section{A. Laboratory Experiment}

A total of 20 prototype FSM transducers were manufactured as explained in Section III by PIC GmbH [10]. These transducers were then tested under laboratory conditions to validate the FEA results in Section II-B. $1 \mathrm{~m}$ square $6.25 \mathrm{~mm}$ thick mild steel plate was chosen to match the material properties assumed for FEA in Section II-B. Retroreflective tapes [34] were attached on the plate with a radius of $0.4 \mathrm{~m}$ from the center of the plate. Polytec 3D PSV-400 scanning vibrometer [35] was used to monitor the signals $0.4 \mathrm{~m}$ away from the excitation. This type of experimental setup is validated to be accurate in order to characterize transducers in the literature by Haig et al. [24]. $90 \mathrm{kHz} 5$-cycle Hann-windowed pulse was used as the input tone-burst, and the transducer was driven by the commercially available UGW system Teletest. The experimental setup is illustrated in Fig. 9.

Laboratory experimental results are illustrated in Fig. 10. The propagation directionality of wave modes is plotted against 


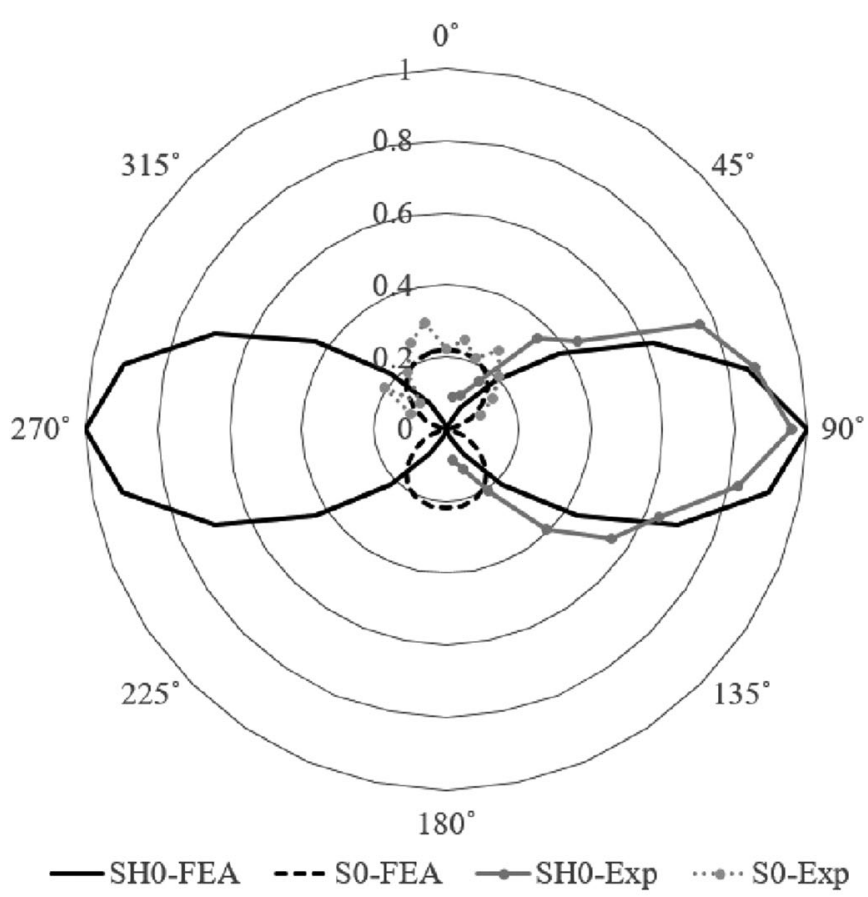

(a)

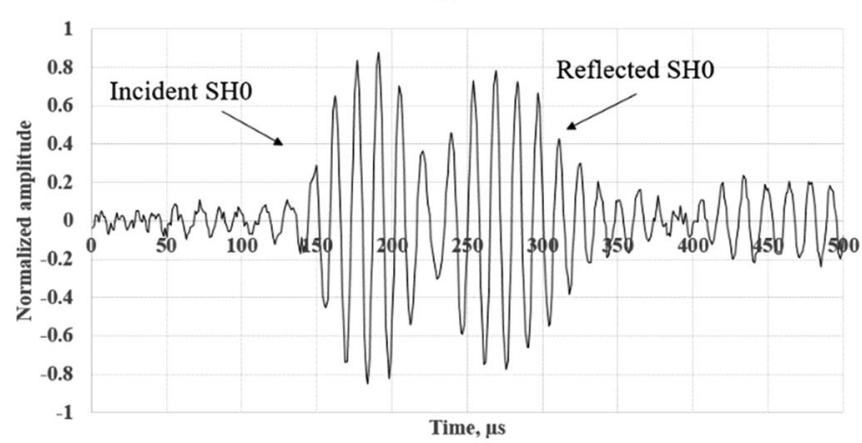

(b)

Fig. 10. Laboratory experimental results at $90 \mathrm{kHz}$. (a) Polar plot illustrating the propagation directionality of the proposed FSM transducer and the vertical axis represents the normalized amplitude and (b) timedomain data illustrating the monitored data at $90^{\circ}$. normalized FEA results [see Fig. 10(a)]. A0 mode is eliminated due to being buried within the noise level. Directionality patterns of the proposed FSM transducer match with FEA results. This illustrates that the SH0 mode can be excited perpendicular to the axis of vibration by the proposed FSM transducer. Timedomain data collected at $90^{\circ}$ are illustrated in Fig. 10(b). The first pulse to arrive is the incident SH0 followed by the reflected SH0 from the near edge. These results can be used to verify that the propagation direction of $\mathrm{SHO}$ is perpendicular to the axis of vibration. Numerical and experimental $\mathrm{ToA}$ of $\mathrm{SH} 0$ is presented in Table III.

\section{B. Field Trials}

Field trials were performed on a $4 \mathrm{~m}$ diameter liquid storage tank to study the UGW propagation across the tank floor. The tank floor surface is undulated due to corrosion. Thickness of
TABLE III

COMPARISON OF NUMERICAL AND EXPERIMENTAL RESULTS-TOA OF SHO Mode Generated by the Proposed FSM TRANSDUCER 0.4 M AWAY FROM THE POINT OF EXCITATION, WHICH CORRESPONDS TO THE INFORMATION SHOWN IN FIG. 10

\begin{tabular}{cccc}
\hline \hline Mode & $\begin{array}{c}\text { Velocity, } \\
V_{\mathrm{gr}}(\mathrm{m} / \mathrm{ms})\end{array}$ & $\begin{array}{c}\text { Numerical } \\
\text { ToA }(\mu \mathrm{s})\end{array}$ & $\begin{array}{c}\text { Experimental } \\
\text { ToA }(\mu \mathrm{s})\end{array}$ \\
\hline SH0 & 3.2 & 125 & 127 \\
\hline \hline
\end{tabular}

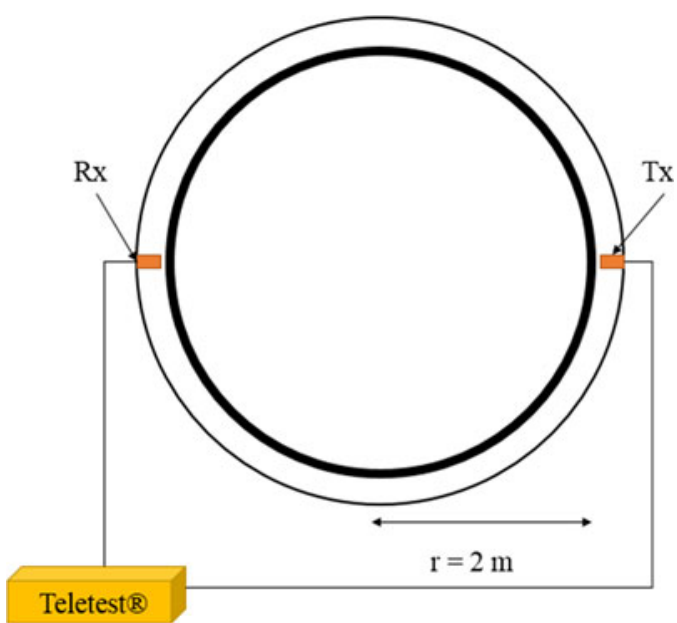

Fig. 11. Setup of the field trials and attached sensors.

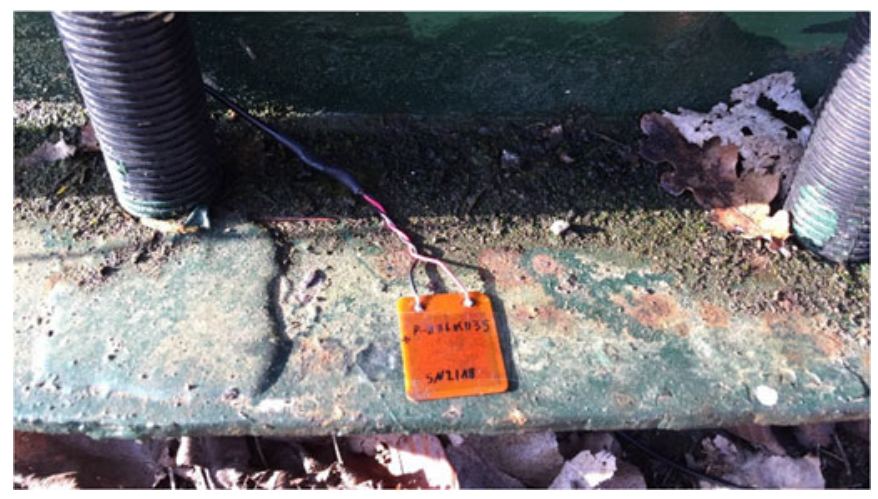

Fig. 12. Attached FSM transducer on the $4 \mathrm{~m}$ diameter tank floor without any surface preparation.

the floor plate is $6.25 \mathrm{~mm}$. Two transducers were attached on 313 opposite sides of the tank floor plate (see Fig. 11). Transduc- 314 ers were bonded to the surface using an acrylic adhesive, and 315 during the curing process, transducers were held in place with 316 a magnet to achieve a rigid surface contact. The Teletest UGW 317 system was used to drive the FSM transducer. The data collec- 318 tion was in pitch-catch configuration in order to identify excited 319 modes discretely. A frequency sweep was conducted from 20 to 320 $120 \mathrm{kHz}$ with $1 \mathrm{kHz}$ increments. Hann-windowed pulse mod- 321 ulation was applied to excite a discrete input signal. Fig. 13322 illustrates the contour plot for the acquired data (frequency 323 range of $20-120 \mathrm{kHz}$ ) and also time-domain representation at 324 $60 \mathrm{kHz}$. 


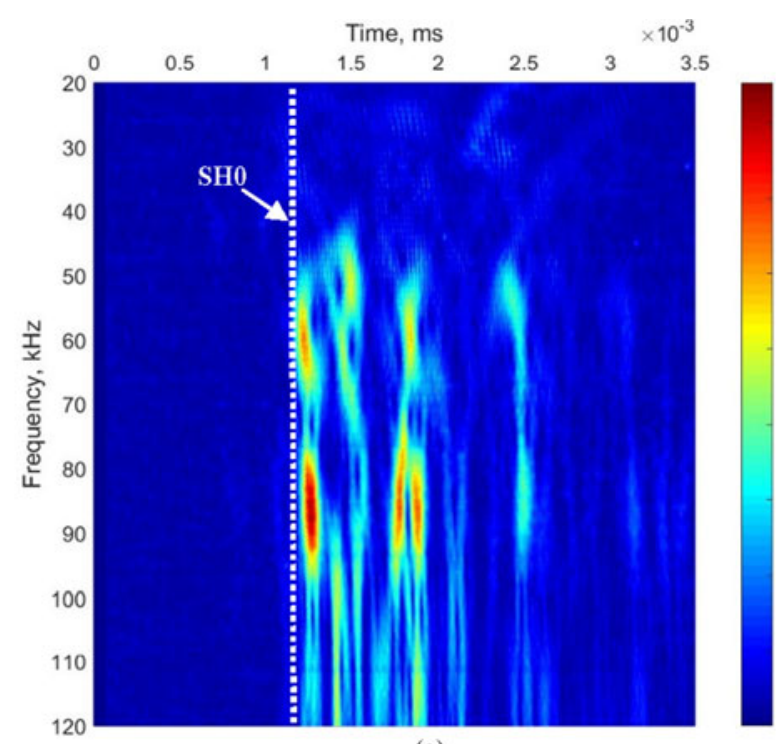

(a)

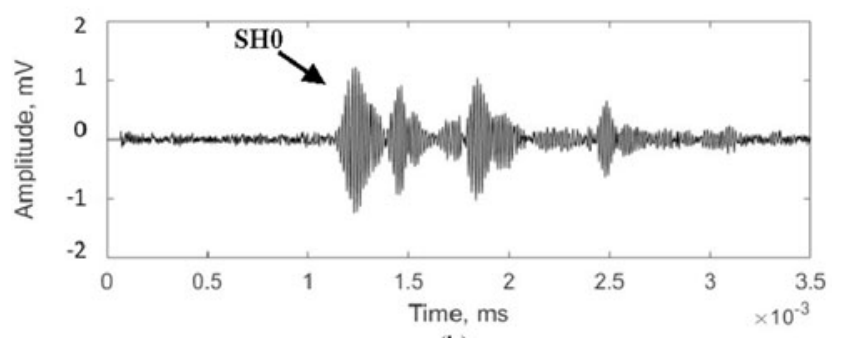

(b)

Fig. 13. Field trial results (proposed FSM transducer). (a) Contour plot over $20-120 \mathrm{kHz}$ with $1 \mathrm{kHz}$ increments (dashed line represents the ToA of $\mathrm{SHO}$ ) and (b) time-domain data at $60 \mathrm{kHz}$.

\section{Performance Review of the Proposed FSM TRANSDUCER}

In this study, an FSM transducer was investigated to operate at the UGW operating frequency range $(20-120 \mathrm{kHz})$ to excite the SH0 mode perpendicular to the axis of vibration. As illustrated in Fig. 2, the SH0 mode should propagate perpendicular to the axis of vibration. However, commercially available flexible MFC transducers excite SHO diagonally rather than perpendicular to the axis of vibration [24]. This complicates the signal processing and transducer bonding process. In order to overcome this problem, PIC investigated on modifying their current DuraAct patch transducers to excite the SHO mode for low-frequency UGW applications.

\section{A. Numerical Simulations and Laboratory Trials}

An FEA was performed to study the characteristics and directionality of the proposed FSM transducer. FEA results are illustrated in Figs. 4 and 5. These results illustrate that the propagation of SHO is perpendicular to the axis of vibration. SH0 has been predominantly excited compared to S0 and A0 modes. Time-domain results in Fig. 5 illustrate that the A0 mode has comparatively low amplitude, which can be neglected in experimental trials as it is buried within the $6 \mathrm{~dB}$ noise level.

Laboratory trials were conducted to validate FEA results in Section II-B. Experimental results are in good agreement

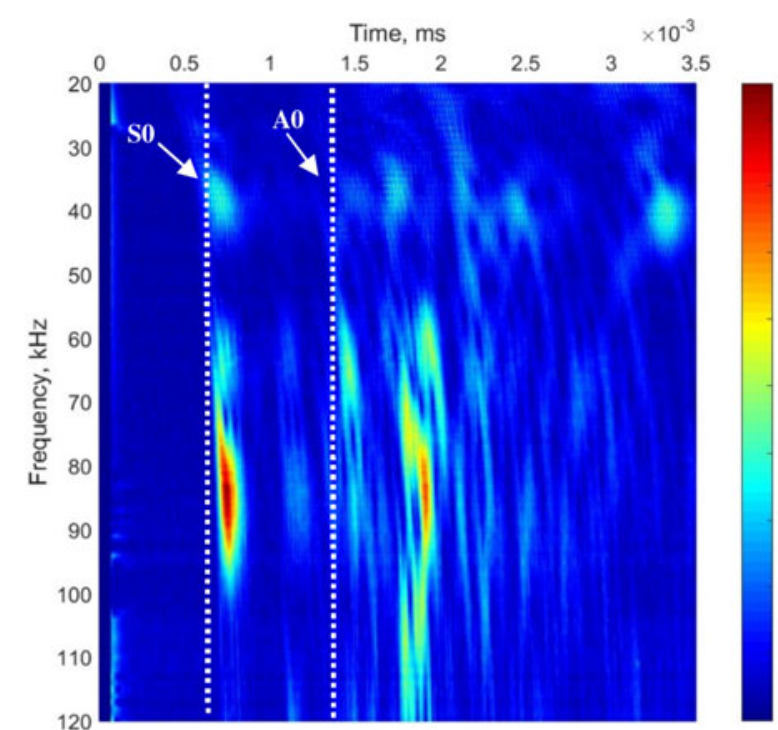

(a)

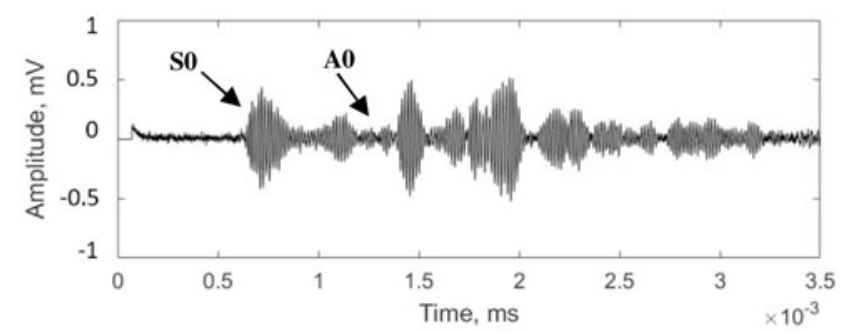

(b)

Fig. 14. Field trial results (MFC transducer [9]). (a) Contour plot over 20-120 kHz with $1 \mathrm{kHz}$ increments (dashed lines represent the ToA of $\mathrm{SO}$ and $\mathrm{AO}$ ) and (b) time-domain data at $60 \mathrm{kHz}$.

with FEA results, which corresponds to the directionality of 350 the FSM transducer. Time-domain data received at $90^{\circ}$ shown 351 in Fig. 10(b) confirms the directional excitation of SH0. Only 352 pulses present are the incident SH0 mode and the reflected SHO 353 mode from the near edge [see Fig. 10(b)]. Table III summarizes 354 the ToA of SH0 from FEA and experimental trials; it has an 355 error of $2 \mu \mathrm{s}$, which is due to the potential assumed material 356 property mismatch.

\section{B. Field Trials}

As explained in Section I, the primary application of the proposed FSM is to excite the SH0 mode to examine the structural health of above ground liquid storage tank floors. Therefore, FSM transducers were installed on to a field tank to study the amplitude response over a range of frequencies. The dashed line in Fig. 13(a) highlights the ToA of the SHO mode and it is also the first mode to arrive. The fastest mode (SO) in the UGW frequency range is suppressed due to the directional excitation of SH0.

Commercially available MFC transducers are also investigated in this study as they are currently used to inspect the tank floor using Lamb modes [36]. The same experimental setup is used, as illustrated in Fig. 11. MFC transducers use only S0 for inspection due to the complex propagation directionality of SHO [24]. Experimental results are illustrated in Fig. 14 and dashed 
TABLE IV

Field Trial Results of the Proposed FSM and MFC [9] TRANSDUCERS-TOA OF EACH MONITORED MODE 4 M AWAY FROM THE POINT OF EXCITATION COMPARED TO THE EXPECTED TOA, WHICH CORRESPONDS TO THE RESULTS SHOWN IN FIGS. 13 AND 14

\begin{tabular}{llll}
\hline \hline & S0 & SH0 & A0 \\
\hline Excitation & MFC & FSM & MFC \\
Velocity, $V_{\mathrm{gr}}(\mathrm{m} / \mathrm{ms})$ & 5.4 & 3.2 & 2.6 \\
Expected ToA $(\mu \mathrm{s})$ & 740 & 1250 & 1538 \\
Monitored ToA $(\mu \mathrm{s})$ & 698 & 1214 & 1356 \\
Error $(\%)$ & 5.6 & 2.8 & 11.8 \\
\hline \hline
\end{tabular}

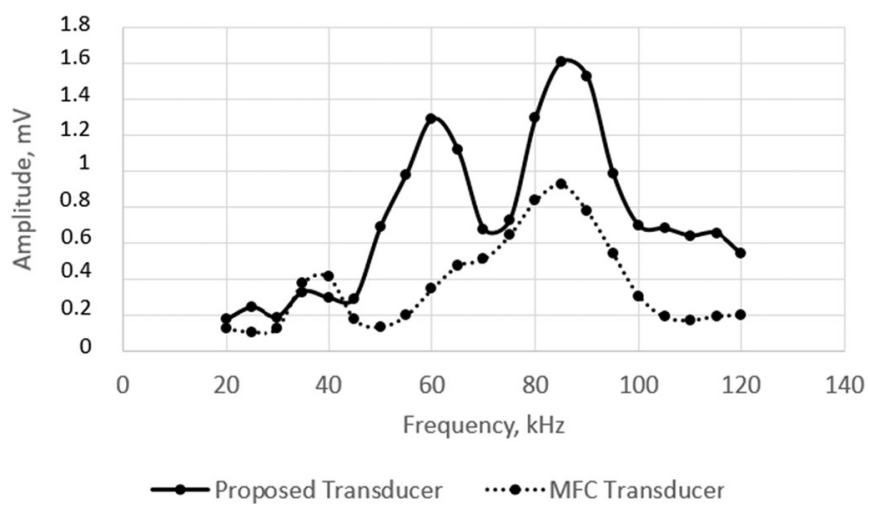

Fig. 15. Amplitude response of investigated transducers (proposed FSM and MFC [9] transducers) over a range of frequencies.

lines in contour plot represent the ToA of S0 and A0. First mode to arrive is the fastest S0 mode. The monitored field trial ToA information is summarized against the expected ToA at $60 \mathrm{kHz}$ in Table IV.

Amplitude response over a range of frequencies for the mode of interest from FSM and MFC (SH0 and S0, respectively) is summarized in Fig. 15. Based on the results illustrated in Fig. 15, FSM transducer has high amplitude response compared to the MFC transducer for the studied application. Both transducers investigated in this study exhibit a broadband frequency response; however, due to the excitability, it shows a high amplitude response at the regions of 55-65 and $80-90 \mathrm{kHz}$ for both transducers. The excitability of a particular mode is defined by the ratio of surface displacement of that mode to applied force when both quantities are measured at the location of interest and the direction [37]. The surface displacement caused by a transducer depends on the material and geometric features of the structure under inspection, which, therefore, cause high amplitude response for certain frequencies due to resonance [38].

\section{Applications and Further Work}

Based on the characteristics of the proposed FSM transducer, it can be used to assess the structural degradation of assets using UGW for following applications:

1) Tank floor inspection,

2) Pipe inspection,

3) Bridge inspection,

4) Railway rail inspection, and

5) Composite inspection.
The FSM transducer has a better surface contact compared to the conventional rigid UGW transducers due to its flexibility. However, adaptability of the FSM transducer to other structures has to be investigated and quantified in future studies. Furthermore, defect sensitivity and performance at elevated temperature of the proposed FSM transducer have to be assessed in relation to SHM applications mentioned above. A controlled experiment can be conducted by introducing a growing defect to acquire data over elevating temperatures. The proposed transducer also has the potential to be used in medical applications to obtain a better contact due to its flexibility; this will be investigated in future studies.

\section{CONCLUSION}

SHM using UGW is a mature field but can be advanced by achieving higher quality assessment of structural health. There is a gap in the knowledge to improve UGW transducers and their surface contact with structures. As a solution, much research has been conducted on flexible transducers for UGW applications. The present study investigated a flexible transducer, which can be used to excite the SHO mode perpendicular to the axis of vibration. The proposed FSM transducer can be used to advance the quality of UGW inspection on structural health. The directionality of the proposed transducer is investigated using FEA, and numerical results are validated using the 3-D laser vibrometer under laboratory conditions. Then, field trials were performed to investigate the amplitude response over a frequency range of $20-120 \mathrm{kHz}$ on a liquid storage tank. Commercially available Teletest Focus+ UGW system was used in both laboratory and field experiments to drive the transducer. The proposed transducer can improve the surface contact on irregular surfaces as an inherent feature. Compared to the commercially available MFC transducer, FSM transducer has a high amplitude response. This transducer can also ease the signal processing due to the directional excitation of $\mathrm{SH} 0$ and open up new applications of SHM using UGW.

\section{REFERENCES}

[1] J. L. Rose, Ultrasonic Guided Waves in Solid Media. Cambridge, U.K.: Cambridge Univ. Press, 2014.

[2] D. N. Alleyne and P. Cawley, "The practical excitation and measuremen of Lamb waves using piezoelectric transducers," Rev. Prog. Quant. Nondestruct. Eval., vol. 13, pp. 181-188, 1994.

[3] R. B. Williams, D. J. Inman, and W. K. Wilkie, "Temperature-dependent thermoelastic properties for macro fiber composite actuators," J. Therm. Stresses, vol. 27, pp. 903-915, 2004.

[4] M. Predoi and A. Negrea, "Ultrasonic guided waves sensitivity to flaws near plate edge," Univ. "Politehnica" Bucharest Sci. Bull., Ser. D, Mech. Eng., vol. 72, pp. 17-22, 2010

[5] R. S. C. Monkhouse, P. D. Wilcox, and P. Cawley, "Flexible interdigital PVDF transducers for the generation of Lamb waves in structures," Ultrasonics, vol. 35, no. 7, pp. 489-498, 1997.

[6] A. J. Brunner, M. Babezat, P. Flueler, and C. Huber, "Composites from piezoelectric fibers as sensors and emitters for acoustic applications," $J_{.} \quad 453$ Acoust. Emission, vol. 22, pp. 127-138, 2004.

[7] W. K. Wilkie et al., "Low-cost piezocomposite actuator for structural 455 control applications," in Proc. SPIE's 7th Annu. Int. Symp. Smart Struct. 456 Mater., Newport Beach, CA, 2000.

[8] G. Harvey, A. Gachagan, J. W. Mackersie, T. McCunnie, and R. Banks, "Flexible ultrasonic transducers incorporating piezoelectric fibres," IEEE Trans. Ultrason., Ferroelectr., Freq. Control, vol. 56, no. 9, pp. 1999-2009, Sep. 2009. 
[9] Smart Material Corp., "Macro fiber composite - MFC" 20032017. [Online]. Available: http://www.smart-material.com/MFC-productmain.html. Accessed on: Jan. 16, 2017.

[10] PI Ceramic GmbH, "DuraAct piezoelectric transducers," 1996-2017. [Online]. Available: https://www.piceramic.com/en/products/piezoceramicactuators/patch-transducers/. Accessed on: Jan. 16, 2017.

[11] P. Wierach, "Development of multifunctional materials systems with piezoceramic foils in the lead project adaptronics," in Proc. Adaptronic Congr., 2003.

[12] W. Hillger and A. Szewieczek, "Impact detection in a composite tail-boom structure with ultrasonic imaging- and guided waves techniques," in Proc. 10th Eur. Conf. Non-Destruct. Test., Moscow, 2010.

[13] D. Schmidt, D. Habas, and N. Dobmann, "Manufacturing of CFRP panels with integrated sensor network and contacting of the network," in Smart Intelligent Aircraft Structures. Cham, Switzerland: Springer, 2015, pp. 605-615.

[14] Z. S. Khodaei and M. H. Aliabadi, "A multi-level decision fusion strategy for condition based maintenance of composite structures," Materials, vol. 790, 2016, Art. no. E790.

[15] M. S. Salmanpour, Z. S. Khodaei, and M. H. Aliabadi, "Airborne transducer integrity under operational environment for structural health monitoring," Sensors, vol. 12, 2016, Art. no. 2110.

[16] M. Gall and B. Thielicke, "Life-span investigations of piezoceramic patch sensors and actuators," Proc. SPIE, Behav. Mech. Multifunct. Composite Mater, vol. 6526, 2007, Art. no. 65260P.

[17] T. Heber, M. Gude, and W. Hufenbach, "Production process adapted design of thermoplastic-compatible piezoceramic modules," Composites A, vol. 59, pp. 70-77, 2014.

[18] A. Gachagan, G. Hayward, and R. Banks, "A flexible piezoelectric transducer design for efficient generation and reception of ultrasonic Lamb waves," IEEE Trans. Ultrason., Ferroelectr., Freq. Control, vol. 52, no. 7, pp. 1175-1182, Jul. 2005

[19] M. Kobayashi, C. Jen, and D. Lévesque, "Flexible ultrasonic transducers," IEEE Trans. Ultrason., Ferroelectr., Freq. Control, vol. 53, no. 8, pp. 14781486, Aug. 2006.

[20] C. Yin, C. Chiu, W. Tsai, and J. Chen, "Flexible transducers for guided wave structural health monitoring of porous composite plates," in Proc. 19th World Conf. Non-Destruct. Test., Munich, 2016.

[21] C. R. Bowen, L. R. Bradley, D. P. Almond, and P. D. Wilcox, "Flexible piezoelectric transducer for ultrasonic inspection," Ultrasonics, vol. 48, pp. 367-375, 2008.

[22] C. Yin and W. Tsai, "Flexible ultrasonic transducers for transverse horizontal plate waves," in Proc. IEEE Int. Ultrason. Symp., Taipei, 2015, pp. $1-4$.

[23] P. S. Lowe, W. Duan, J. Kanfoud, and T.-H. Gan, "Structural health monitoring of above-ground storage tank floors by ultrasonic guided wave excitation on the tank wall," Sensors, vol. 17, no. 11, 2017, Art. no. E2542.

[24] A. G. Haig, R. M. Sanderson, P. J. Mudge, and W. Balachandran, "Macrofibre composite actuators for the transduction of Lamb and horizontal shear ultrasonic guided waves," Insight, Non-Destruct. Test. Condition Monit., vol. 55, no. 2, pp. 72-77, 2013.

[25] P. J. Mudge, A. M. Lank, and D. N. Alleyne, "A long range method of detection of corrosion under insulation in process pipework," J. JSNDI, vol. 46, pp. 314-319, 1997.

[26] P. S. Lowe, R. M. Sanderson, N. V. Boulgouris, A. G. Haig, and W. Balachandran, "Inspection of cylindrical structures using the first longitudinal guided wave mode in isolation for higher flaw sensitivity," IEEE Sens. J., vol. 16, no. 3, pp. 706-714, Feb. 2016.

[27] Abacus-SIMULIA, Abacus Version 6.13 User's Manual, Abacus, Waltham, MA, USA, 2013.

[28] Z. Sharif-Khodaei and M. H. Aliabadi, "Assessment of delay-and-sum algorithms for damage detection in aluminium and composite plates," Smart Mater. Struct., vol. 23, no. 7, 2014, Art. no. 07500.

[29] P. S. Lowe, R. Sanderson, N. V. Boulgouris, and T.-H. Gan, "Hybrid active focusing with adaptive dispersion for higher defect sensitivity in guided wave inspection of cylindrical structures," Nondestruct. Test. Eval., vol. 31, no. 3, pp. 219-234, 2015.

[30] B. Pavlakovic, M. Lowe, D. Alleyne, and P. Cawley, "Disperse: A general purpose program for creating dispersion curves," Rev. Prog. Quant. Nondestruct. Eval., vol. 16, pp. 185-192, 1997.

[31] G. Boivin, M. Viens, and P. Belanger, "Development of a low frequency shear horizontal piezoelectric transducer for the generation of plane $\mathrm{SH}$ waves," AIP Conf. Proc., vol. 1706, 2016, Art. no. 030019.

[32] PI Ceramics, "Piezoelectric ceramic components," PI Ceramics, Lederhose, Germany, 2007.
[33] D. N. Alleyne and M. J. S. Lowe, "The reflection of guided waves from circumferencial notches in the pipe," ASME J., vol. 65, pp. 635-641, 1998

[34] Polytec Ltd., "Retroreflective tape," 2017. [Online]. Available: http:/ www.polytec.com/uk/products/vibration-sensors/vibrometer-accessories/ surface-preparation/retroreflective-tape/. Accessed on: Jan. 18, 2017.

[35] Polytec Ltd., "PSV-500-3D scanning vibrometer," 2017. [Online]. Available: http://www.polytec.com/uk/products/vibration-sensors/scanningvibrometers/psv-500-3d-scanning-vibrometer/. Accessed on: Jan. 18, 2017.

[36] L. Mažeika, R. Kažys, R. Raišutis, and R. Šliteris, "Ultrasonic guided wave tomography for the inspection of the fuel tanks floor," in Proc. 4th Int. Conf. NDT, 2007.

[37] P. Wilcox, M. J. S. Lowe, and P. Cawley, "Mode and transducer selection for long range Lamb wave inspection," J. Intell. Mater. Syst. Struct. vol. 12 , no. 8, pp. 553-565, 2001.

[38] P. Belanger, "Feasibility of thickness mapping using ultrasonic guided waves," Ph.D. dissertation, Imperial College, London, U.K., 2009.

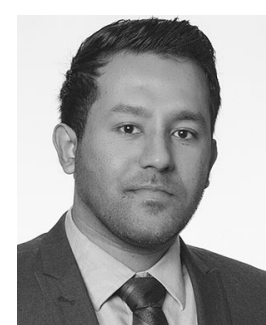

Premesh S. Lowe (S'13-M'16) received the Ph.D. degree from the Electrical and Computer Engineering Department, Brunel University London, Uxbridge, U.K., in 2016.

He commenced his career in the field of nondestructive testing by joining the Integrity Management Group of TWI Ltd., Cambridge, as a Research Engineer in 2012. Since 2015, he has been working as a Research Fellow with the Brunel Innovation Centre, Cambridge, U.K. His research is focused on finite element methods and signal processing on ultrasonic guided wave. He has authored o co-authored more than 20 peer-reviewed journals and conferences. His research interests include ultrasonic sensor development, sound energy focusing, and fouling removal using high power ultrasonics.

Dr. Lowe has been serving as a Reviewer for the IEEE Journals, NDT\&E, and Sensors Journal since 2014. He is an executive member of the IEEE UK\&I Section serving as the Chapter Officer since 2017.

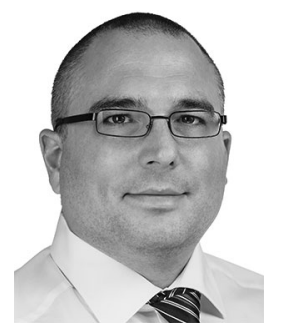

Timo Scholehwar received the Engineering degree in materials science from the Technical University Dresden, Dresden, Germany, in 2002, and the Ph.D. degree in 2011.

He started out as an Assistant Researcher with the Fraunhofer IKTS, Dresden, Germany, in 1997. In 2007, he became an Engineer for Piezo Components and Devices, PI Ceramic $\mathrm{GmbH}$ Lederhose, Germany, and a Senior Design Engineer for Piezo Materials and Components in 2017.

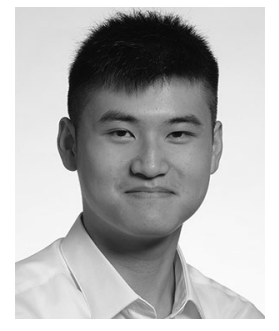

Jimmy Yau was born in Hong Kong. He is currently working toward the B.Eng. degree in mechanical engineering at the University of Surrey, Guildford, U.K.

In 2016, he joined the Brunel Innovation Centre, Uxbridge, U.K., as a Project Technical Assistant and he was involved in ultrasonic sensor and encapsulation design. His research interests include sensor development, numerical methods, and structural health monitoring. 


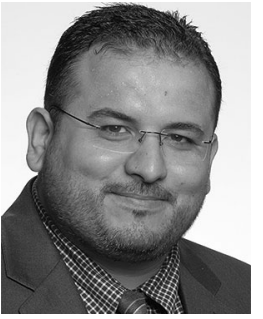

Jamil Kanfoud received the Master's degree in general engineering from l'Ecole Polytechnique de Tunisie, Tunisia, and the M.Phil. degree in numerical modeling from l'Université de Technologie de Compiègne, Compiègne, France.

$\mathrm{He}$ is a Technical Manager with the Brunel Innovation Centre, Uxbridge, U.K. Before joining Brunel University, he worked on modeling and optimizing a novel porous noise canceling solution for the Ariane $\mathrm{V}$ launcher fairings using BIOT-Allard theory. He has five years' academic experience, including two years heading the Electromechanical Department, ESPRIT. At TWI, he worked on active and passive vibration damping, and developed condition and structural health monitoring strategies and technologies for aerospace, renewable energy, and oil and gas using techniques ranging from vibration to acoustic emission. Since joining Brunel University, he has been working on developing research areas in nondestructive testing and condition monitoring including the development of novel sensing techniques (plenoptic cameras), the adoption of machine learning for inspection, and monitoring applications. He has a track record of proposing and managing collaborative projects and building strategic partnerships with industrial partners to increase technology readiness level of novel technologies in the field of structural integrity.

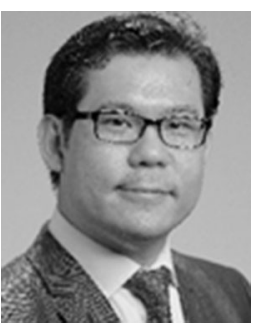

Tat-Hean Gan received the Graduate degree (first-class honors) in electrical and electronics engineering from the University of Nottingham, Nottingham, U.K., the M.Sc. degree (distinction) in advanced mechanical engineering in 1998 and the Ph.D. degree in engineering specializing in advanced ultrasonic imaging from the University of Warwick, Coventry, U.K., and the Executive MBA degree from the University of Birmingham, Birmingham, U.K., in 2006.

He has worked as an academic and in the industry for many years. He is currently a Professor with Brunel University London, Uxbridge, U.K., where he is also the Chair of acoustic waves technologies with the School of Engineering and Design. He is also an Associate Director of TWI Ltd., and the Technology Director of the National Structural Integrity Research Centre, the U.K.'s first industry-led postgraduate education and research center in structural integrity. He has authored or co-authored more than 100 papers and has contributed to several books in the field of nondestructive testing. His research interests include signal and image processing, sensor development, asset integrity management, and structural assessment.

Dr. Gan has received CEng, Eurlng, and IntPE (U.K.) status and is also a Fellow of the Institute of Engineering and Technology, British Institute of Non-Destructive Testing, International Society of Condition Monitoring, and International Society of Engineering Asset Management. He was a recipient of The Welding Institute Lidstone Award who is deemed to have made the most significant contribution to the advancement of welding technology.

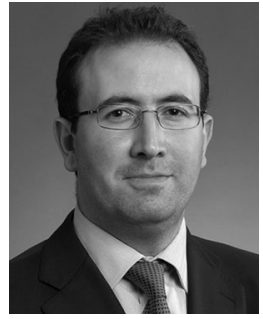

Cem Selcuk is the Business Development Con- 649 sultant and the Manager for Innovation Acceler- 650 ators with TWI Ltd., Great Abington, U.K. He was 651 the Manager and the Head of the Brunel Innova- 652 tion Centre. He is an active professional mem- 653 ber of the EPMA, APMI, IOM3 (FIMMM), and 654 The Welding Institute (FWeldI). He has been the 655 Chairman of the Particulate Engineering Com- 656 mittee, hence a member of the Materials Sci- 657 ence and Technology Board of the IOM3. He 658 has more than 190 citations to his publications 659 (more than 70) in peer-reviewed journals. He has presented at numerous 660 international conferences, authored book chapters and industrial project 661 reports, and contributed to white papers.

Mr. Selcuk has both served as a Referee and an Editor. He sits on 662 the editorial board of Powder Metallurgy, the official journal of EPMA. 663 


\section{Queries}

Q1. Author: Please note that Refs. [18] and [20] were identical, and Ref. [20] has been deleted. The subsequent references have been renumbered. Please check.

Q2. Author: Please provide the citation of Fig. 12 in the text.

Q3. Author: Please provide the page range in Refs. [7], [11], [12], [20], and [36].

Q4. Author: Please check Ref. [31] as set for correctness.

Q5. Author: Please provide the areas of study in which Premesh S. Lowe received the Ph.D. degree and Tat-Hean Gan received the Executive MBA degree.

Q6. Author: Please provide the area of study and the institution's name in which Timo Scholehwar received the Ph.D. degree.
Q7. Author: Please check the edits made to the educational details of Timo Scholehwar, and correct if necessary.

Q8. Author: Please provide the year in which Jamil Kanfoud received the Master's and M.Phil. degrees, and Tat-Hean Gan received the Graduate and Ph.D. degrees.

Q9. Author: Please provide the educational details of Cem Selcuk. 


\title{
Flexible Shear Mode Transducer for Structural Health Monitoring Using Ultrasonic Guided Waves
}

\author{
Premesh S. Lowe, Member, IEEE, Timo Scholehwar, Jimmy Yau, Jamil Kanfoud, Tat-Hean Gan, \\ and Cem Selcuk
}

\begin{abstract}
The application of the fundamental shearhorizontal wave mode for guided wave structural health monitoring is undoubtedly beneficial due to its nondispersive characteristics. Existing guided wave shear mode transducers are rigid and brittle, because of these characteristics, bonding them to irregular surfaces (i.e., curved surfaces) is challenging. There is a huge market interest in the development of a flexible shear mode transducer, which eases the transducer bonding process onto irregular surfaces and improves the surface contact between the transducer and the structure. This study presents a flexible shear mode transducer for structural health monitoring using low-frequency guided waves $(20-120 \mathrm{kHz})$. The proposed transducer is manufactured using piezoceramic, and based on the results of this study, it exhibits the directional excitation of fundamental shear-horizontal mode at $20-120 \mathrm{kHz}$. Finite element analysis and laboratory experiments were conducted to study the behavior of the proposed transducer. Field trials were conducted on a liquid storage tank with an undulated surface (due to corrosion). The performance of the proposed transducer is also compared to the commercially available macro fiber composite transducers. The proposed transducer was driven by the industrialized ultrasonic guided wave inspection system; Teletest Focus + in line with the application of tank floor inspection using ultrasonic guided waves.
\end{abstract}

Index Terms-Directionality, flexibility, industrialization, shear mode transducer, structural health monitoring (SHM), ultrasonic guided wave (UGW). TRUCTURAL health monitoring (SHM) of degrading engineering structures due to various factors (such as corrosion) is important as degradation could lead to structural

Manuscript received August 5, 2017; revised September 14, 2017 , October 23, 2017, and November 2, 2017; accepted November 12, 2017. Paper no. TII-17-1775. (Corresponding author: Premesh S. Lowe.)

P. S. Lowe, J. Yau, J. Kanfoud, and T.-H. Gan are with Brunel University London, Uxbridge UB8 3PH, U.K. (e-mail: shehan.lowe@brunel.ac.uk; jimmy.yau@brunel.ac.uk; jamil.kanfoud@brunel.ac.uk; tat-hean.gan@ brunel.ac.uk).

T. Scholehwar is with PI Ceramic GmbH, Lindenstrasse 07589, Germany (e-mail: t.scholehwar@piceramic.de).

C. Selcuk is with The Welding Institute Ltd., Great Abington CB21 6AL, U.K. (e-mail: cem.selcuk@twi.co.uk).

Color versions of one or more of the figures in this paper are available online at http://ieeexplore.ieee.org.

Digital Object Identifier 10.1109/TII.2017.2775343 instability causing harm to the industry and the environment. Low-frequency $(20-120 \mathrm{kHz})$ ultrasonic guided waves (UGWs) are widely used to inspect the structural health of elongated structures (i.e., pipes, plates, rails, cables) due to their inherent feature of long-range propagation [1]. Commercial UGW systems have evolved vastly over two decades to fulfill industry requirements. The development of UGW transducers is a core aspect with great interest, particularly for the inspection of complex structures (such as floor of liquid storage tanks). Early research on transducer development for commercial UGW systems has been conducted by Alleyne and Cawley, where they developed a transducer with thickness-shear motion to excite Lamb waves on a plate [2]. The development of flexible transducers for UGW application became imperative since early 2000 with the interest of inspecting structures with curved and/or irregular surfaces [3], [4].

Piezoelectric films (polyvinylidene fluoride, PVDF) is one of the earliest flexible transducers for UGW application [5]. PVDF transducers are flexible and durable. Compared to lead zirconate titanate (PZT), PVDF requires higher actuation power and heavy amplification. PVDFs work better in a higher frequency range $(0.5-4 \mathrm{MHz})$ [5], and this limits the long-range propagation capabilities of UGW due to the typically higher attenuation rates at these frequencies. Another transducer was developed by combining the electromechanical efficiency of PZT with mechanical flexibility. Examples of these are active fiber composite (AFC) and macro fiber composite (MFC) [3]. AFC and MFC are thin piezoceramic fibers that are aligned unidirectionally and exploit the use of interdigitated electrodes, which deliver a stronger longitudinal piezoelectric effect along the length of fibers [4]. This is performed by applying an electric field in the direction of fiber axis, which in turn generates a stronger longitudinal $\left(d_{33}\right.$ constant) piezoelectric effect. AFCs operate in low hundreds of $\mathrm{kHz}$ range [6] and $\mathrm{MFCs}$ operate in tens of $\mathrm{kHz}$ to $\mathrm{MHz}$ range [7], [8]. The main advantage of MFCs in comparison to AFCs and PVDFs is the reduced manufacturing cost. MFCs are mass manufactured and distributed by Smart Material Corp. [9].

The patch transducer is a piezoceramic-based flexible transducer (commercial name-DuraAct), which was designed by German Aerospace Centre and is manufactured and distributed by PI Ceramic (PIC) GmbH [10]. The DuraAct transducer operates in $\mathrm{kHz}$ to $\mathrm{MHz}$ range depending on the application requirement [11]. DuraAct transducers were initially used to detect the 
impact of a tail boom structure in 2010 using guided waves [12]. Since then, DuraAct transducers are used for many applications using UGWs in different frequency ranges. DuraAct transducers have gained a higher interest in the Aerospace industry to inspect composite materials [13], [14]. Compared to other flexible transducers, DuraAct transducers have proven to survive under harsh environmental conditions [15]. Standard MFCs cannot operate beyond $80^{\circ} \mathrm{C}$, whereas DuraAct can operate up to $150-200^{\circ} \mathrm{C}$, though the mechanical flexibility is limited at these temperatures. Lifespan of piezoceramic patch transducers was investigated in 2007 [16]. A key parameter investigated in this study was the flexibility of piezoceramic patch transducers by studying the performance of the transducer under tensile stress. As an outcome, minimum bending radius $\left(r_{\min }\right)$ can be calculated as follows and it depends on the ceramic thickness:

$$
r_{\min }=8 . e^{t .4 .4}
$$

where $e$ is the Euler constant, and $t$ is the thickness of the ceramic layer in $\mathrm{mm}$.

Common features of the aforementioned flexible transducers (PVDF, AFC, MFC, and DuraAct) are flexibility, lightweight [17], and more importantly, these transducers predominantly excite Lamb modes [18]. According to the literature, research on flexible transducer development was limited to excite Lamb modes [18], [19] or they operate at a higher frequency range (above $0.5 \mathrm{MHz}$ [20]-[22].

As stated in the literature, the most preferable UGW mode for the inspection of liquid storage tank floors is the fundamental shear-horizontal wave mode due to the relatively low attenuation and dispersion rates [1], [23]. Based on surface irregularities caused by the corrosion, transducers have to be flexible and cannot be rigid and/or brittle for this application. Currently, commercially available MFC transducers are used to obtain a better surface contact compared to rigid transducers [9]. However, based on directionality patterns of the MFC transducer, only the fundamental symmetric Lamb mode can be used for inspection, as the fundamental shear mode is excited in the diagonal direction, which complicates the signal processing [24]. The MFC transducer generates both fundamental Lamb modes in one direction, which complicates the signal interpretation. There is a higher market interest in the development of a flexible transducer, which generates the fundamental shear-horizontal mode perpendicular to the axis of vibration. According to author's knowledge, no attention has been given to develop a flexible transducer, which predominantly excites shear modes with directionality at low-frequency range $(20-120 \mathrm{kHz})$.

This study presents a flexible transducer, which generates the fundamental shear-horizontal mode perpendicular to the axis of vibration. The frequency range of interest is $20-120 \mathrm{kHz}$ due to the long-range propagation capabilities of UGWs for SHM [1]. The behavior of the proposed transducer was studied using numerical simulations, and laboratory experiments were conducted to validate the numerical results. Proposed transducers were also installed onto a liquid storage tank with an undulated surface (due to corrosion) to study the performance over a range of frequencies. Commercially available Teletest Focus +
UGW system [25] was used to excite the transducer during both laboratory and field trials.

This paper is organized as follows. Numerical simulations are presented in Section II, and the manufacturing process of the proposed flexible shear mode (FSM) transducer is reported in Section III. Laboratory experiments and field trial results are documented in Section IV. Section V presents the performance review of the proposed transducer, followed by the conclusions in Section VI.

\section{NUMERICAL SIMULATION}

\section{A. Finite Element Analysis (FEA)}

Finite element analysis (FEA) has been performed to study the wave propagation behavior (directionality) of the proposed FSM transducer. With increased complexity of the analysis, analytical calculations are no longer practical [26]. A three-dimensional (3-D) model was built to conduct the aforementioned numerical analysis using ABAQUS/ EXPLICIT version 6.13 [27]-[29]. A solid transient analysis was conducted, which is governed by Navier's equation of motion for an isotropic media as follows [1]:

$$
(\lambda+\mu) \nabla \nabla \cdot u+\mu \nabla^{2} u=\rho\left(\frac{\partial^{2} u}{\partial t^{2}}\right)
$$

where $\lambda$ and $\mu$ are Lamé constants, $u$ is the 3-D displacement vector, $\nabla^{2}$ is the 3-D Laplace operator, and $\rho$ is the material density. Unknown potentials governing the Lamb (3) and shear (4) modes can be extracted as follows by substituting the potentials of Helmholtz decomposition into (2):

$$
\begin{aligned}
& \left(\frac{\partial^{2} \emptyset}{\partial t^{2}}\right)=c_{l}^{2} \nabla^{2} \emptyset \\
& \left(\frac{\partial^{2} \Phi}{\partial t^{2}}\right)=c_{s}^{2} \nabla^{2} \Phi
\end{aligned}
$$

where $\emptyset$ is the compressional scalar potential, $\Phi$ is the equivoluminal vector potential, and $c_{l}$ and $c_{s}$ are the velocities of Lamb and shear modes, respectively.

A circular plate was modeled with a $0.4 \mathrm{~m}$ radius and a thickness of $6.25 \mathrm{~mm}$. Dispersion curves for a $6.25 \mathrm{~mm}$ thick steel plate are illustrated in Fig. 1. Dispersion curves are plotted using the commercially available software DISPERSE [30]. The dispersion curve diagram illustrates the velocity of mode in relation to the frequency with separate curves for each existing mode in a frequency range. Based on the geometry and the operating frequency range of the current study, excitable modes are fundamental symmetric Lamb mode S0, asymmetric Lamb mode A0, and shear-horizontal mode SHO. As illustrated in Fig. 1, SH0 is the only nondispersive mode in the UGW operating frequency range, which is of a great interest for UGW inspection [1]. The size of the active ceramic plate of the proposed FSM transducer is $25 \times 25 \times 0.2 \mathrm{~mm}^{3}$ (width, height, and thickness, respectively). The overall actuator size is $38 \times 30 \times$ $0.5 \mathrm{~mm}^{3}$ due to the necessary encapsulation and electrical contacts. Since the difference in volume is passive, it does not have a 

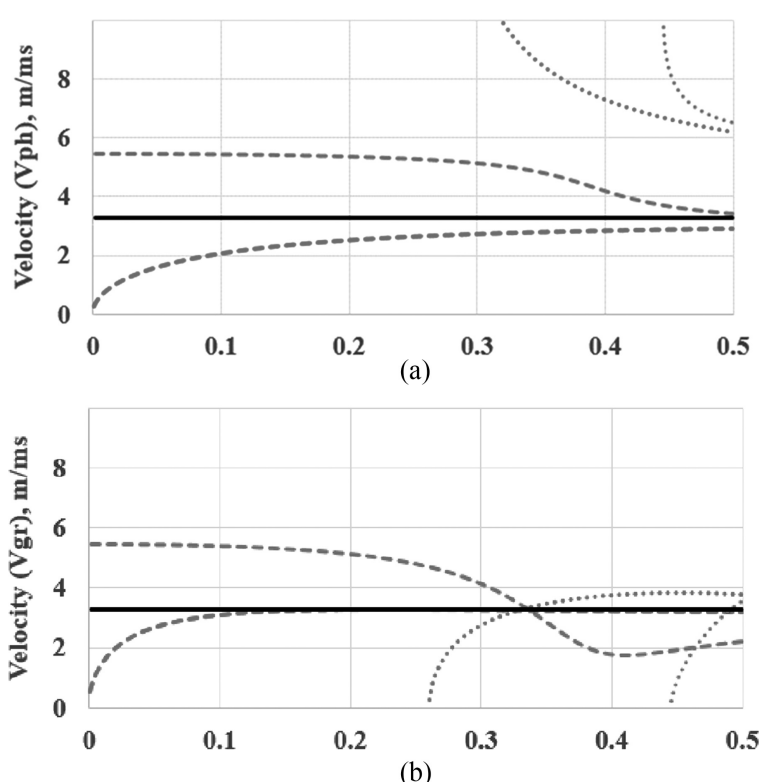

Frequency, $\mathrm{MHz}$

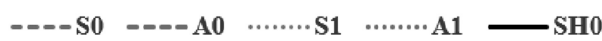

Fig. 1. Dispersion curves for a $6.25 \mathrm{~mm}$ thick steel plate: (a) phase velocity and (b) group velocity.

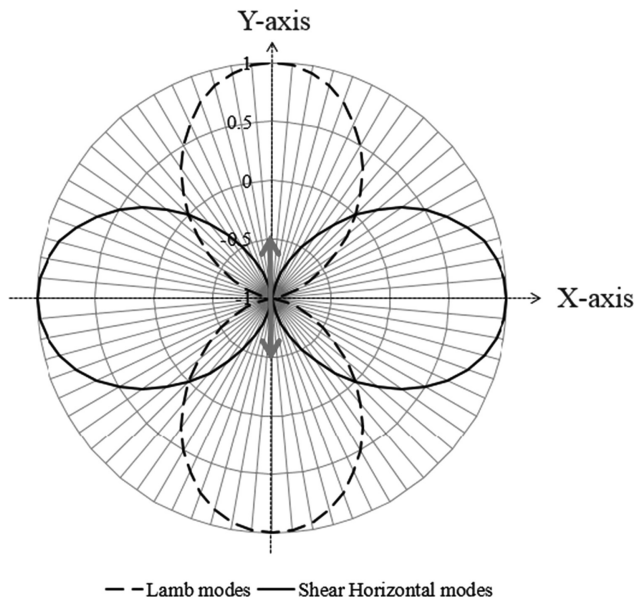

Fig. 2. Directivity pattern of the Lamb and shear-horizontal modes due to the surface shear vibration in the $y$-axis caused by a point source. The vertical axis represents the amplitude.

significant influence on the performance or symmetry of the waves generated.

Theoretical wave propagation directionality of a point source vibrating in-plane is illustrated in Fig. 2 [24]. Unlike Lamb modes, $\mathrm{SH}$ modes propagate perpendicular to the axis of vibration. As shown in Fig. 2, if the transducer vibrates in the $y$-axis, SH mode should propagate in both $x$-axis directions and Lamb modes should propagate in both $y$-axis directions [31]. Assumed material properties for the FEA are presented in Table I. The vibration mode of the modeled PIC 255 soft PZT [32] is the 1-5 thickness-shear mode.

Layout of the FE model is illustrated in Fig. 3. Transducer was bonded at the center of the plate using tie constraint to
TABLE I

Assumed Material Properties for the Numerical Simulation

\begin{tabular}{lcc}
\hline \hline Property & Steel & PIC 255 soft PZT \\
\hline Density $(\rho)$ & $7830 \mathrm{~kg} / \mathrm{m}^{3}$ & $7800 \mathrm{~kg} / \mathrm{m}^{3}$ \\
Young's modulus $(E)$ & $207 \mathrm{GPa}$ & $110 \mathrm{GPa}$ \\
Poisson's ratio $(v)$ & 0.3 & 0.36 \\
Piezoelectric charge $\left(d_{15}\right)$ & & $550 \cdot 1 \mathrm{e}-12 \mathrm{~m} / \mathrm{V}$ \\
Piezoelectric voltage $\left(g_{15}\right)$ & & $37 \cdot 1 \mathrm{e}-3 \mathrm{Vm} / \mathrm{N}$ \\
Coupling factor $\left(k_{15}\right)$ & & 0.66
\end{tabular}

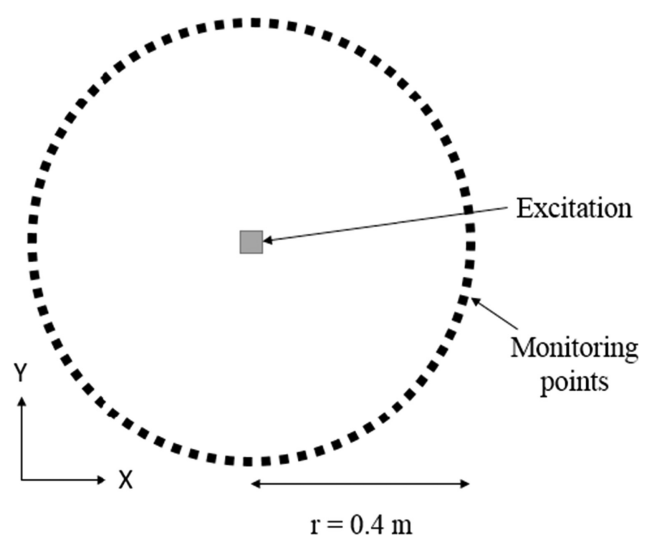

Fig. 3. Layout of the finite element model.

obtain a firm surface contact [27]. Size of mesh elements $\left(h_{o}\right) \quad 194$ was in the range of $3.125-3.13 \mathrm{~mm}$ and calculated as follows: 195

$$
h_{o}=\frac{c}{N f_{o}}
$$

where $c$ is the velocity of the slowest mode, $N$ is the number 196 of elements per wavelength, and $f_{o}$ is the frequency of interest. 197 The linear eight node brick elements with reduced integration 198 (ABAQUS element type C3D8R) were used to achieve efficient 199 computation time, and the mesh refinement was such that there 200 were at least eight elements to represent the smallest possible 201 wavelength in the main lobe of the frequency bandwidth. This 202 level of mesh refinement has been validated in the previous stud- 203 ies [26], [33]. The excitation tone-burst was a $90 \mathrm{kHz} 5$-cycle 204 Hann-windowed pulse. This particular frequency and the num- 205 ber of cycles were chosen in order to individually identify modes 206 due to the length limitation of the modeled plate. Transmitted 207 signals were monitored $0.4 \mathrm{~m}$ away from the excitation.

\section{B. FEA Results}

Numerical results are illustrated in Figs. 4 and 5. Fig. 4 represents contour plots of propagated waves at different time increments and illustrates that the $\mathrm{SH} 0$ mode is predominantly excited in both $x$-axis directions according to the coordinates shown in Fig. 2. The polar plot in Fig. 5(a) validates the above-mentioned claim and matches with the theoretical wave propagation behavior of a shear mode transducer as reported in the literature (see Fig. 2). The time-domain data presented in Fig. 5(b) show that $\mathrm{SH} 0$ is the only propagated mode at $90^{\circ}$. This gives the confidence to use the proposed FSM transducer for the tank floor inspection using UGW due to the predominant and directional

\author{
95
}

96 98 99 00 1

03

04

06




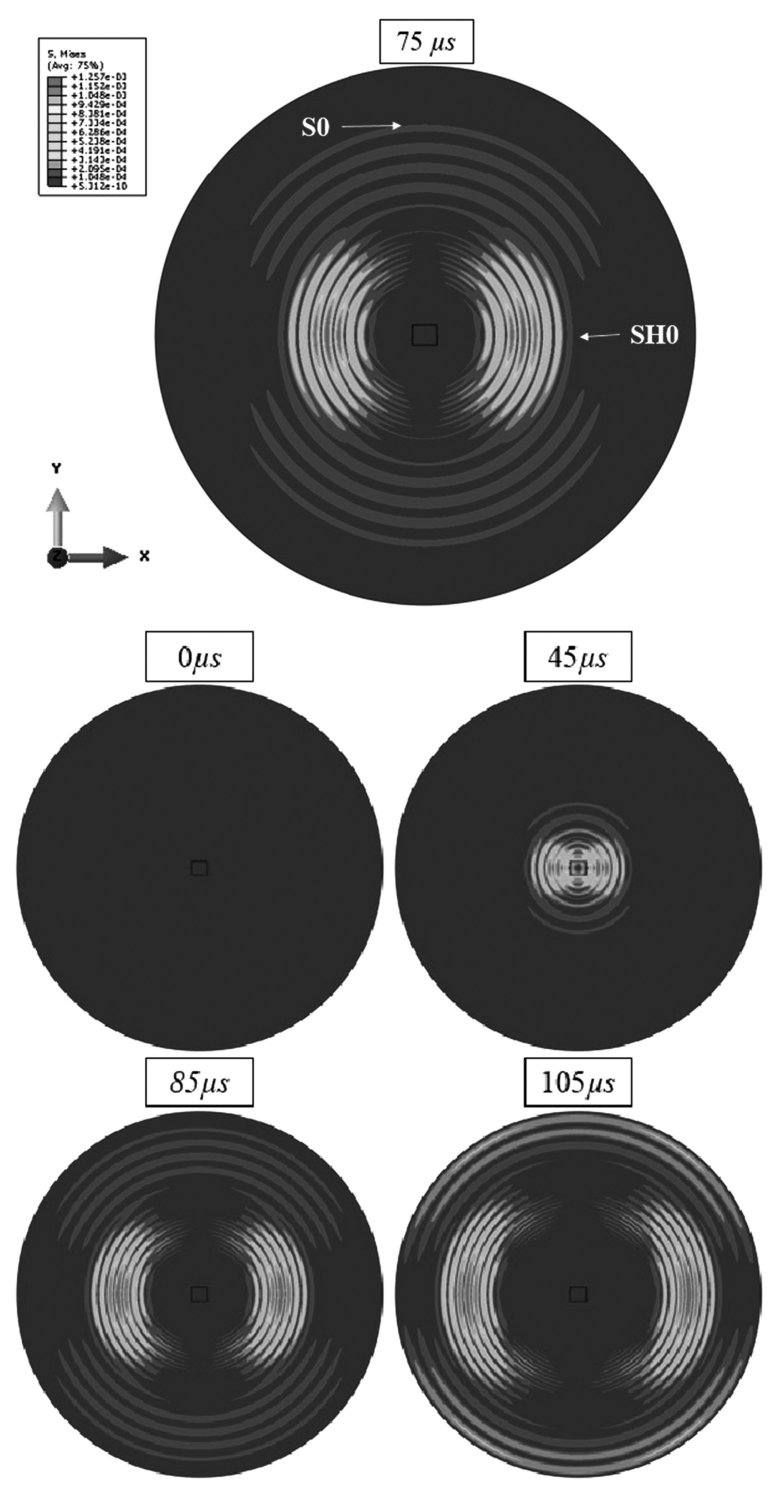

Fig. 4. FEA results; wave propagation at different time increments on a $0.4 \mathrm{~m}$ radius steel plate at $90 \mathrm{kHz}$ and the color scale represents the von-Mises stress. excitation of SH0. This is further investigated in Section IV-B and further discussed in Section V. The first mode to arrive is $\mathrm{SO}$, which is the fastest mode, and then SHO and A0. Time of arrival (ToA) of each mode is presented in Table II, and ToA can be calculated as follows:

$$
\mathrm{ToA}=\frac{x}{V_{\mathrm{gr}}}
$$

where $x$ is the distance of propagation, and $V_{\mathrm{gr}}$ is the group velocity of the mode of interest.

\section{Manufacturing Process of the Proposed Transducer}

The proposed FSM transducer has a similar manufacturing process in relation to the existing DuraAct transducers, which operates longitudinally (see Section I) [12]. Manufacturing process of the proposed transducer is as follows. The first step of

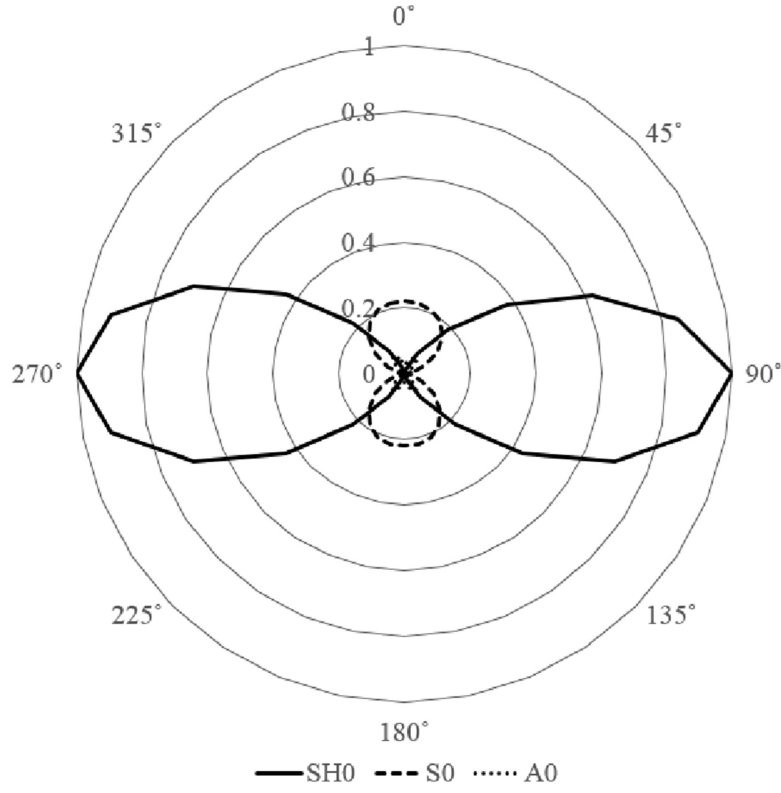

(a)

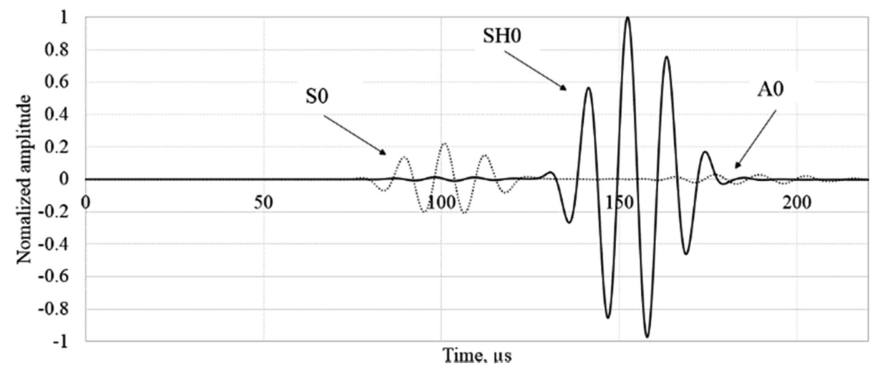

(b)

Fig. 5. Numerical modeling results at $90 \mathrm{kHz}$. (a) Polar plot illustrating the propagation directionality of the proposed shear transducer and the vertical axis represents the normalized amplitude and (b) time-domain data illustrating the monitored data at $0^{\circ}$ (dotted line) and $90^{\circ}$ (solid line).

TABLE II

Numerical Results-ToA of Each Mode Monitored 0.4 M AWAY FROM THE POINT OF EXCITATION, WHICH CORRESPONDS TO THE INFORMATION SHOWN IN FIG. 5

\begin{tabular}{lcc}
\hline \hline Mode & $\begin{array}{c}\text { Velocity, } \\
V_{\mathrm{gr}}(\mathrm{m} / \mathrm{ms})\end{array}$ & $\begin{array}{c}\text { ToA } \\
(\mu \mathrm{s})\end{array}$ \\
\hline S0 & 5.4 & 74 \\
SH0 & 3.2 & 125 \\
A0 & 2.6 & 153 \\
\hline \hline
\end{tabular}

manufacturing the proposed FSM transducer is the production 234 of thickness-shear piezoceramic plates. The PZT material used 235 in the FSM transducer is PIC 255 soft PZT [32]. PZT blocks, 236 approximately in the dimensions of $40 \times 30 \times 25 \mathrm{~mm}^{3}$ are 237 polarized at $2,5-3,5 \mathrm{kV} / \mathrm{mm}$. Followed by cutting blocks into 238 plates at $0^{\circ}$ toward the polarization vector. The polarization is 239 in-plane and marked by a small notch, as illustrated in Fig. 6. 240 Then, electrodes are sputtered and plates are cut to final size 241 (dimensions of the active element are shown in Fig. 6). The 242 production process for these shear plates has to be carried out 243 in ambient temperature (i.e., significantly less than the Curie 244 


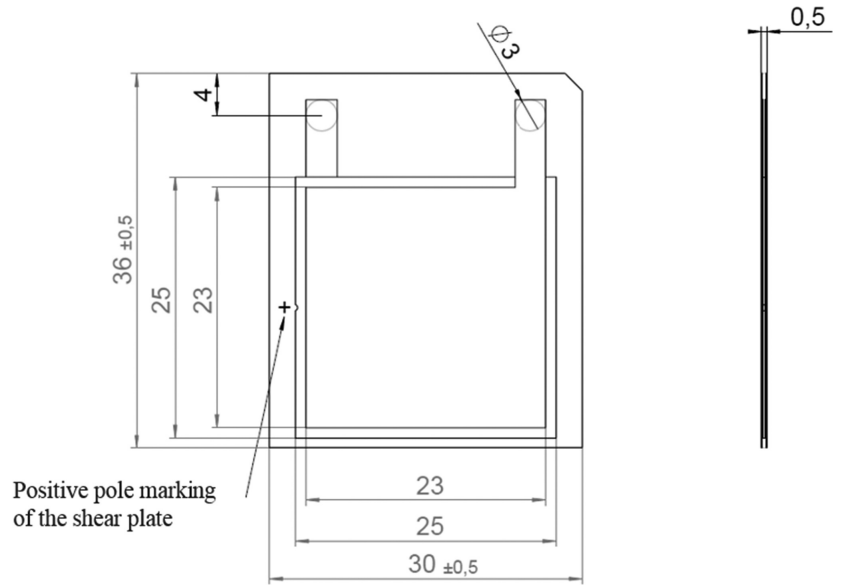

Fig. 6. Schematics of the proposed FSM transducer, dimensions are in $\mathrm{mm}$. Published courtesy of PI Ceramic $\mathrm{GmbH}$.

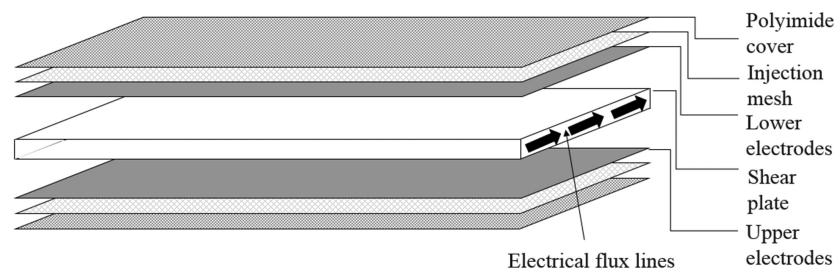

Fig. 7. Different layers in the proposed FSM transducer.

temperature). When an electrical signal is applied to the electrodes, the polarization vector of ferroelectric domains in the material is forced to turn toward the signal field, resulting in an opposite shear movement of electrode surfaces in the direction of the polarization field.

After completion of the production of shear plates, next step is the assembly process. Various layers of the proposed FSM transducer are dry-stacked in an autoclave as follows (see Fig. 7):

1) Polyimide prepreg cover,

2) Lower injection mesh (polyimide),

3) Lower collector electrodes,

4) Manufactured PZT shear plate and the positioning frame,

5) Upper collector electrodes and soldering pads,

6) Upper injection mesh, and

7) Polyimide prepreg cover.

This stack is then sealed on two sides. One open side is connected to a polyimide resin tank and the other is open to the autoclave's vacuum. Then, the autoclave is evacuated and heated up to $\sim 200^{\circ} \mathrm{C}$. The vacuum draws the resin through both injection mesh layers, which is followed by the resin curing. At the final step, transducers were laser-cut from the cured stack. Soldering pads were also uncovered during this process.

Curing of the transducer exerts a permanent lateral pressure of $\sim 44 \mathrm{MPa}$. This in return results in a much tighter potential bending radius because this inner stress has to be overcome before there is any actual negative stress in the surface of the ceramic. This will inherit the flexibility to the proposed transducer, which is an important characteristic in bonding transducers on to an irregular or curved surface. Thickness of the PZT element used in the proposed FSM transducer is $0.2 \mathrm{~mm}$ and

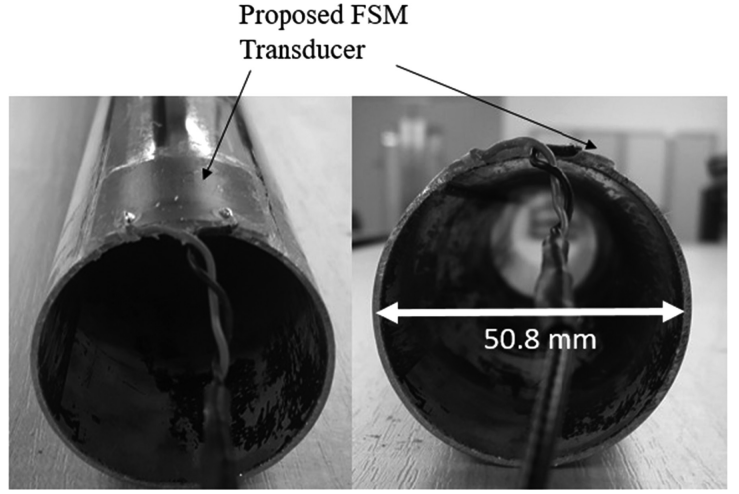

Fig. 8. Photograph of the proposed FSM transducer attached to a $50.8 \mathrm{~mm}$ diameter pipe to illustrate the flexibility of the transducer (illustrating $10 \mathrm{~mm}$ bending radius).

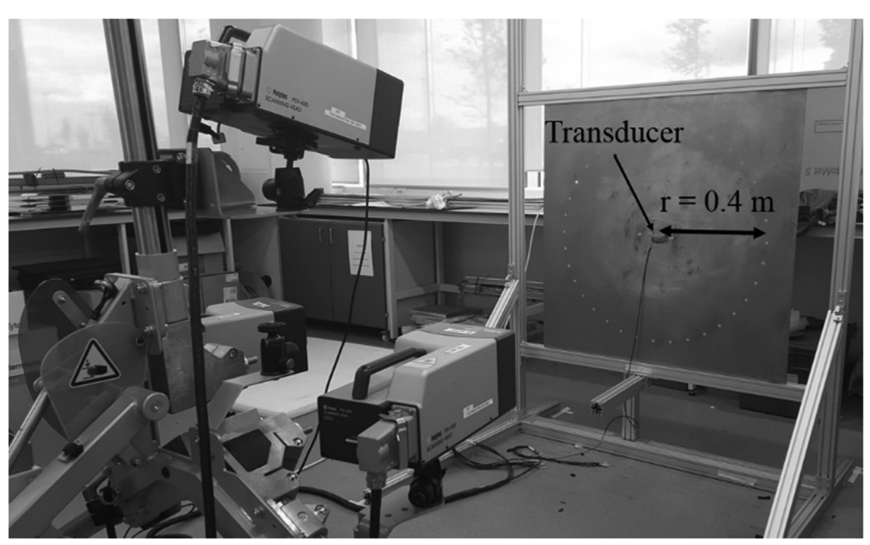

Fig. 9. Laboratory experimental setup.

according to (1), bending radius of the proposed FSM transducer is $20 \mathrm{~mm}$. Photographs of the proposed FSM transducer are shown in Fig. 8. The proposed FSM transducer is attached to the edge of a $50.8 \mathrm{~mm}$ diameter steel pipe using acrylic adhesive showing a $10 \mathrm{~mm}$ bending radius for illustration purposes.

\section{EXPERIMENTAL VALIDATION}

\section{A. Laboratory Experiment}

A total of 20 prototype FSM transducers were manufactured as explained in Section III by PIC GmbH [10]. These transducers were then tested under laboratory conditions to validate the FEA results in Section II-B. $1 \mathrm{~m}$ square $6.25 \mathrm{~mm}$ thick mild steel plate was chosen to match the material properties assumed for FEA in Section II-B. Retroreflective tapes [34] were attached on the plate with a radius of $0.4 \mathrm{~m}$ from the center of the plate. Polytec 3D PSV-400 scanning vibrometer [35] was used to monitor the signals $0.4 \mathrm{~m}$ away from the excitation. This type of experimental setup is validated to be accurate in order to characterize transducers in the literature by Haig et al. [24]. $90 \mathrm{kHz} 5$-cycle Hann-windowed pulse was used as the input tone-burst, and the transducer was driven by the commercially available UGW system Teletest. The experimental setup is illustrated in Fig. 9.

Laboratory experimental results are illustrated in Fig. 10. The propagation directionality of wave modes is plotted against 


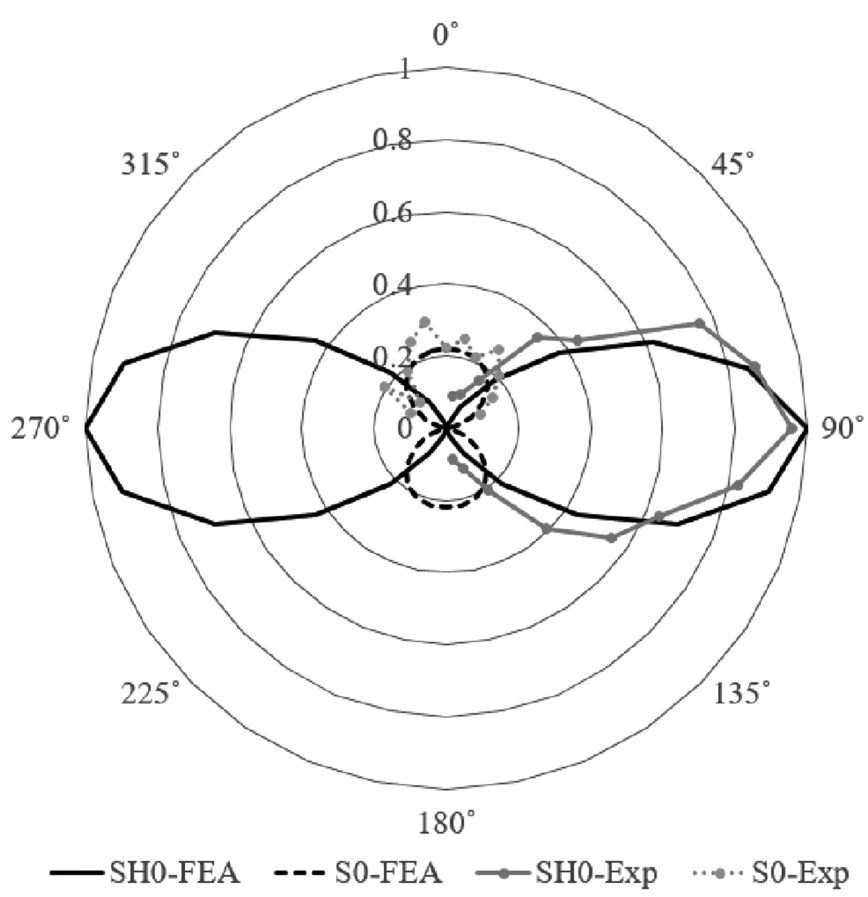

(a)

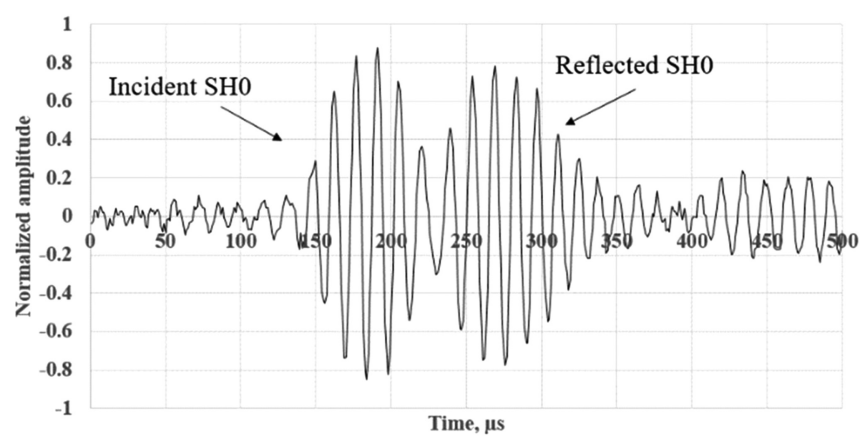

(b)

Fig. 10. Laboratory experimental results at $90 \mathrm{kHz}$. (a) Polar plot illustrating the propagation directionality of the proposed FSM transducer and the vertical axis represents the normalized amplitude and (b) timedomain data illustrating the monitored data at $90^{\circ}$. normalized FEA results [see Fig. 10(a)]. A0 mode is eliminated due to being buried within the noise level. Directionality patterns of the proposed FSM transducer match with FEA results. This illustrates that the SH0 mode can be excited perpendicular to the axis of vibration by the proposed FSM transducer. Timedomain data collected at $90^{\circ}$ are illustrated in Fig. 10(b). The first pulse to arrive is the incident SH0 followed by the reflected SH0 from the near edge. These results can be used to verify that the propagation direction of $\mathrm{SHO}$ is perpendicular to the axis of vibration. Numerical and experimental $\mathrm{ToA}$ of $\mathrm{SH} 0$ is presented in Table III.

\section{B. Field Trials}

Field trials were performed on a $4 \mathrm{~m}$ diameter liquid storage tank to study the UGW propagation across the tank floor. The tank floor surface is undulated due to corrosion. Thickness of
TABLE III

COMPARISON OF NUMERICAL AND EXPERIMENTAL RESULTS-TOA OF SHO Mode Generated by the Proposed FSM Transducer 0.4 M AWAY FROM THE POINT OF EXCITATION, WHICH CORRESPONDS TO THE INFORMATION SHOWN IN FIG. 10

\begin{tabular}{cccc}
\hline \hline Mode & $\begin{array}{c}\text { Velocity, } \\
V_{\mathrm{gr}}(\mathrm{m} / \mathrm{ms})\end{array}$ & $\begin{array}{c}\text { Numerical } \\
\text { ToA }(\mu \mathrm{s})\end{array}$ & $\begin{array}{c}\text { Experimental } \\
\text { ToA }(\mu \mathrm{s})\end{array}$ \\
\hline SH0 & 3.2 & 125 & 127 \\
\hline \hline
\end{tabular}

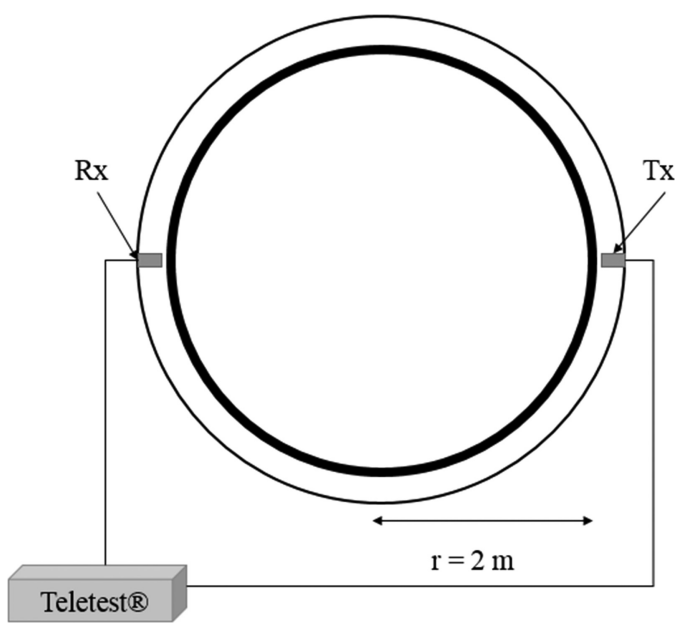

Fig. 11. Setup of the field trials and attached sensors.

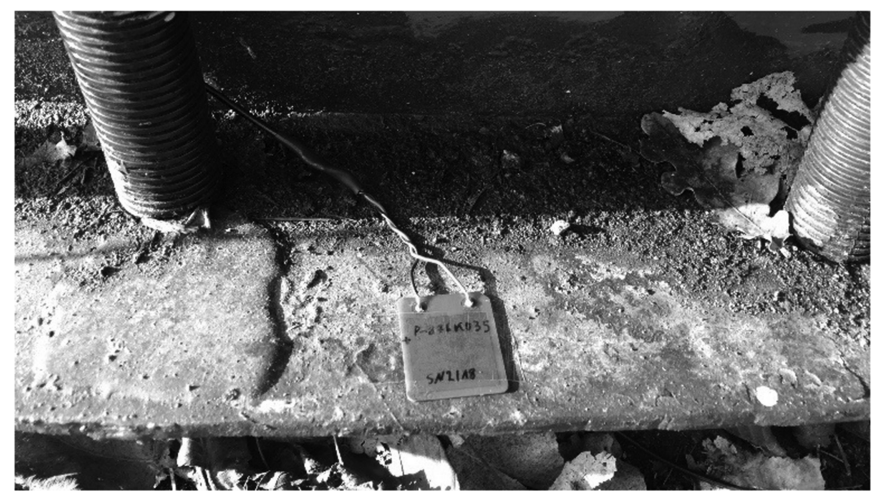

Fig. 12. Attached FSM transducer on the $4 \mathrm{~m}$ diameter tank floor without any surface preparation.

the floor plate is $6.25 \mathrm{~mm}$. Two transducers were attached on 313 opposite sides of the tank floor plate (see Fig. 11). Transduc- 314 ers were bonded to the surface using an acrylic adhesive, and 315 during the curing process, transducers were held in place with 316 a magnet to achieve a rigid surface contact. The Teletest UGW 317 system was used to drive the FSM transducer. The data collec- 318 tion was in pitch-catch configuration in order to identify excited 319 modes discretely. A frequency sweep was conducted from 20 to 320 $120 \mathrm{kHz}$ with $1 \mathrm{kHz}$ increments. Hann-windowed pulse mod- 321 ulation was applied to excite a discrete input signal. Fig. 13 illustrates the contour plot for the acquired data (frequency 323 range of $20-120 \mathrm{kHz}$ ) and also time-domain representation at 324 $60 \mathrm{kHz}$. 


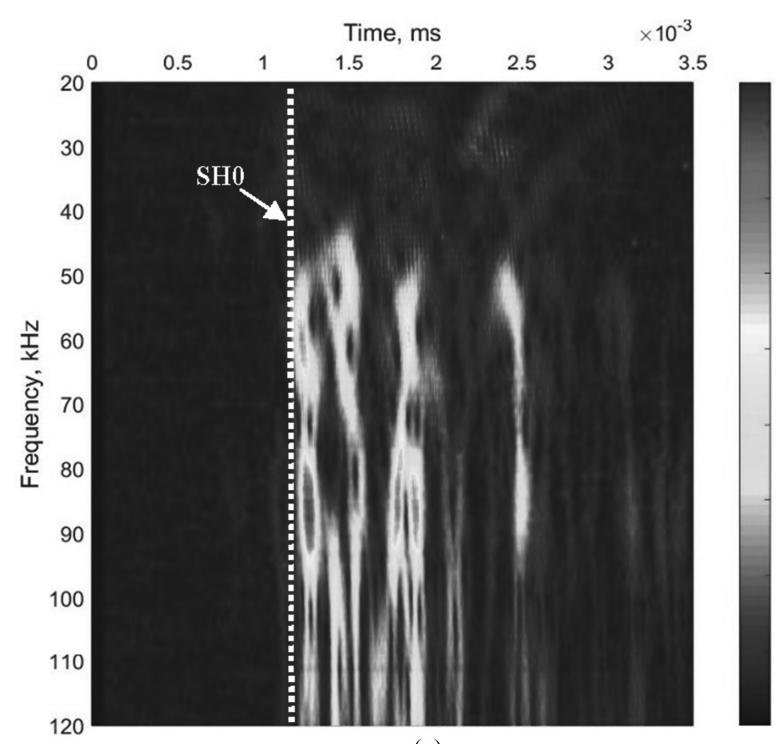

(a)

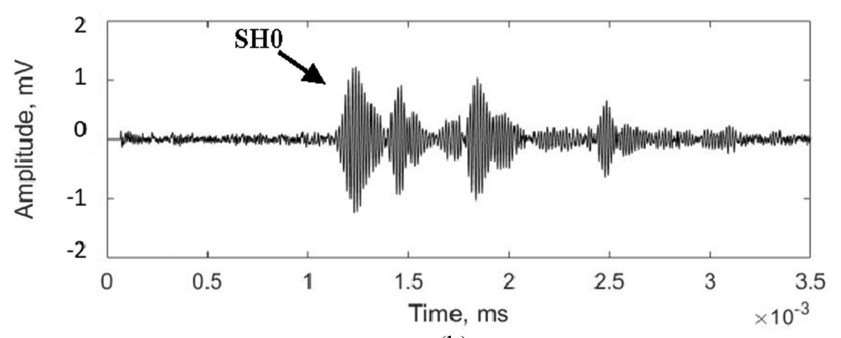

(b)

Fig. 13. Field trial results (proposed FSM transducer). (a) Contour plot over $20-120 \mathrm{kHz}$ with $1 \mathrm{kHz}$ increments (dashed line represents the ToA of $\mathrm{SHO}$ ) and (b) time-domain data at $60 \mathrm{kHz}$.

\section{Performance Review of the Proposed FSM TRANSDUCER}

In this study, an FSM transducer was investigated to operate at the UGW operating frequency range $(20-120 \mathrm{kHz})$ to excite the SH0 mode perpendicular to the axis of vibration. As illustrated in Fig. 2, the SH0 mode should propagate perpendicular to the axis of vibration. However, commercially available flexible MFC transducers excite SHO diagonally rather than perpendicular to the axis of vibration [24]. This complicates the signal processing and transducer bonding process. In order to overcome this problem, PIC investigated on modifying their current DuraAct patch transducers to excite the SHO mode for low-frequency UGW applications.

\section{A. Numerical Simulations and Laboratory Trials}

An FEA was performed to study the characteristics and directionality of the proposed FSM transducer. FEA results are illustrated in Figs. 4 and 5. These results illustrate that the propagation of SHO is perpendicular to the axis of vibration. SH0 has been predominantly excited compared to S0 and A0 modes. Time-domain results in Fig. 5 illustrate that the A0 mode has imental trials as it is buried within the $6 \mathrm{~dB}$ noise level.

Laboratory trials were conducted to validate FEA results in Section II-B. Experimental results are in good agreement comparatively low amplitude, which can be neglected in exper-

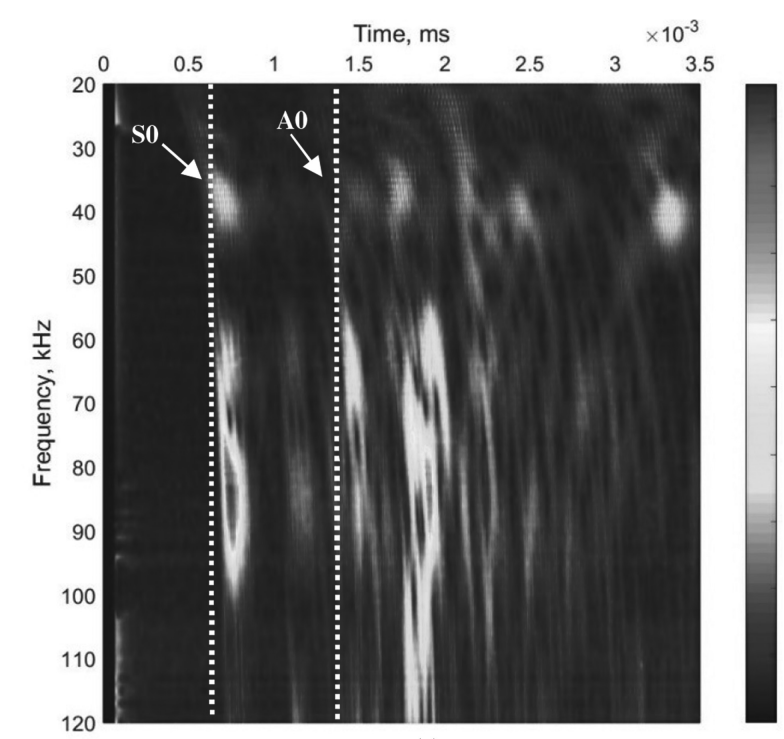

(a)

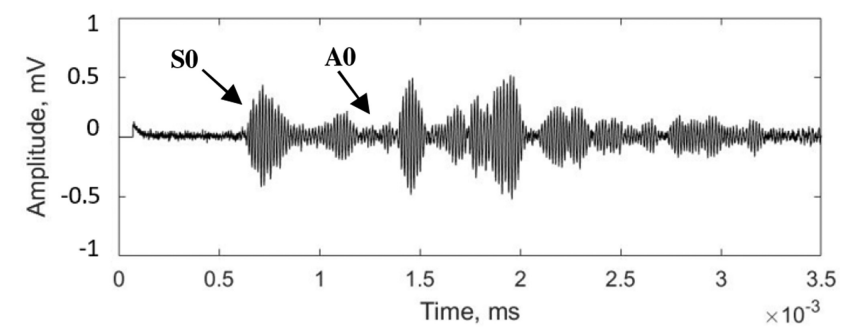

(b)

Fig. 14. Field trial results (MFC transducer [9]). (a) Contour plot over 20-120 kHz with $1 \mathrm{kHz}$ increments (dashed lines represent the ToA of $\mathrm{SO}$ and $\mathrm{AO}$ ) and (b) time-domain data at $60 \mathrm{kHz}$.

with FEA results, which corresponds to the directionality of 350 the FSM transducer. Time-domain data received at $90^{\circ}$ shown 351 in Fig. 10(b) confirms the directional excitation of SHO. Only 352 pulses present are the incident SH0 mode and the reflected SHO 353 mode from the near edge [see Fig. 10(b)]. Table III summarizes 354 the ToA of SH0 from FEA and experimental trials; it has an 355 error of $2 \mu \mathrm{s}$, which is due to the potential assumed material 356 property mismatch.

\section{B. Field Trials}

As explained in Section I, the primary application of the proposed FSM is to excite the SH0 mode to examine the structural health of above ground liquid storage tank floors. Therefore, FSM transducers were installed on to a field tank to study the amplitude response over a range of frequencies. The dashed line in Fig. 13(a) highlights the ToA of the SHO mode and it is also the first mode to arrive. The fastest mode (SO) in the UGW frequency range is suppressed due to the directional excitation of SH0.

Commercially available MFC transducers are also investigated in this study as they are currently used to inspect the tank floor using Lamb modes [36]. The same experimental setup is used, as illustrated in Fig. 11. MFC transducers use only S0 for inspection due to the complex propagation directionality of SH0 [24]. Experimental results are illustrated in Fig. 14 and dashed 
TABLE IV

Field Trial Results of the Proposed FSM ANd MFC [9] TRANSDUCERS-TOA OF EACH MONITORED MODE 4 M AWAY FROM THE POINT OF EXCITATION COMPARED TO THE EXPECTED TOA, WHICH CORRESPONDS TO THE RESULTS SHOWN IN FIGS. 13 AND 14

\begin{tabular}{llll}
\hline \hline & S0 & SH0 & A0 \\
\hline Excitation & MFC & FSM & MFC \\
Velocity, $V_{\mathrm{gr}}(\mathrm{m} / \mathrm{ms})$ & 5.4 & 3.2 & 2.6 \\
Expected ToA $(\mu \mathrm{s})$ & 740 & 1250 & 1538 \\
Monitored ToA $(\mu \mathrm{s})$ & 698 & 1214 & 1356 \\
Error $(\%)$ & 5.6 & 2.8 & 11.8 \\
\hline \hline
\end{tabular}

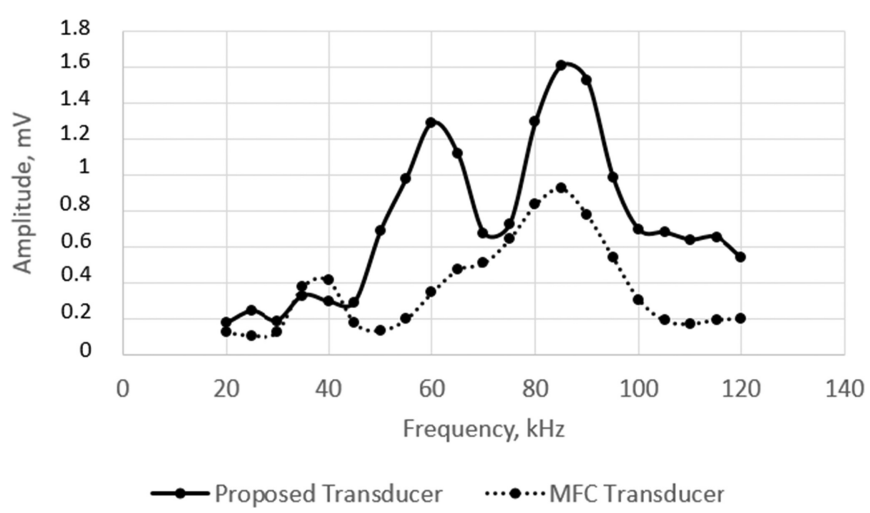

Fig. 15. Amplitude response of investigated transducers (proposed FSM and MFC [9] transducers) over a range of frequencies. lines in contour plot represent the ToA of S0 and A0. First mode to arrive is the fastest S0 mode. The monitored field trial ToA information is summarized against the expected ToA at $60 \mathrm{kHz}$ in Table IV.

Amplitude response over a range of frequencies for the mode of interest from FSM and MFC (SH0 and S0, respectively) is summarized in Fig. 15. Based on the results illustrated in Fig. 15, FSM transducer has high amplitude response compared to the MFC transducer for the studied application. Both transducers investigated in this study exhibit a broadband frequency response; however, due to the excitability, it shows a high amplitude response at the regions of 55-65 and $80-90 \mathrm{kHz}$ for both transducers. The excitability of a particular mode is defined by the ratio of surface displacement of that mode to applied force when both quantities are measured at the location of interest and the direction [37]. The surface displacement caused by a transducer depends on the material and geometric features of the structure under inspection, which, therefore, cause high amplitude response for certain frequencies due to resonance [38].

\section{Applications and Further Work}

Based on the characteristics of the proposed FSM transducer, it can be used to assess the structural degradation of assets using UGW for following applications:

1) Tank floor inspection,

2) Pipe inspection,

3) Bridge inspection,

4) Railway rail inspection, and

5) Composite inspection.
The FSM transducer has a better surface contact compared to the conventional rigid UGW transducers due to its flexibility. However, adaptability of the FSM transducer to other structures has to be investigated and quantified in future studies. Furthermore, defect sensitivity and performance at elevated temperature of the proposed FSM transducer have to be assessed in relation to SHM applications mentioned above. A controlled experiment can be conducted by introducing a growing defect to acquire data over elevating temperatures. The proposed transducer also has the potential to be used in medical applications to obtain a better contact due to its flexibility; this will be investigated in future studies.

\section{CONCLUSION}

SHM using UGW is a mature field but can be advanced by achieving higher quality assessment of structural health. There is a gap in the knowledge to improve UGW transducers and their surface contact with structures. As a solution, much research has been conducted on flexible transducers for UGW applications. The present study investigated a flexible transducer, which can be used to excite the SHO mode perpendicular to the axis of vibration. The proposed FSM transducer can be used to advance the quality of UGW inspection on structural health. The directionality of the proposed transducer is investigated using FEA, and numerical results are validated using the 3-D laser vibrometer under laboratory conditions. Then, field trials were performed to investigate the amplitude response over a frequency range of $20-120 \mathrm{kHz}$ on a liquid storage tank. Commercially available Teletest Focus + UGW system was used in both laboratory and field experiments to drive the transducer. The proposed transducer can improve the surface contact on irregular surfaces as an inherent feature. Compared to the commercially available MFC transducer, FSM transducer has a high amplitude response. This transducer can also ease the signal processing due to the directional excitation of $\mathrm{SH} 0$ and open up new applications of SHM using UGW.

\section{REFERENCES}

[1] J. L. Rose, Ultrasonic Guided Waves in Solid Media. Cambridge, U.K.: Cambridge Univ. Press, 2014.

[2] D. N. Alleyne and P. Cawley, "The practical excitation and measurement of Lamb waves using piezoelectric transducers," Rev. Prog. Quant. Nondestruct. Eval., vol. 13, pp. 181-188, 1994.

[3] R. B. Williams, D. J. Inman, and W. K. Wilkie, "Temperature-dependent thermoelastic properties for macro fiber composite actuators," J. Therm. Stresses, vol. 27, pp. 903-915, 2004.

[4] M. Predoi and A. Negrea, "Ultrasonic guided waves sensitivity to flaws near plate edge," Univ. "Politehnica" Bucharest Sci. Bull., Ser. D, Mech. Eng., vol. 72, pp. 17-22, 2010.

[5] R. S. C. Monkhouse, P. D. Wilcox, and P. Cawley, "Flexible interdigital PVDF transducers for the generation of Lamb waves in structures," Ultrasonics, vol. 35, no. 7, pp. 489-498, 1997.

[6] A. J. Brunner, M. Barbezat, P. Flueler, and C. Huber, "Composites from piezoelectric fibers as sensors and emitters for acoustic applications," J. 453 Acoust. Emission, vol. 22, pp. 127-138, 2004.

[7] W. K. Wilkie et al., "Low-cost piezocomposite actuator for structural 455 control applications," in Proc. SPIE's 7th Annu. Int. Symp. Smart Struct. 456 Mater., Newport Beach, CA, 2000.

[8] G. Harvey, A. Gachagan, J. W. Mackersie, T. McCunnie, and R. Banks, "Flexible ultrasonic transducers incorporating piezoelectric fibres," IEEE Trans. Ultrason., Ferroelectr., Freq. Control, vol. 56, no. 9, pp. 1999-2009, Sep. 2009. 
[9] Smart Material Corp., "Macro fiber composite - MFC," 2003 2017. [Online]. Available: http://www.smart-material.com/MFC-productmain.html. Accessed on: Jan. 16, 2017.

[10] PI Ceramic GmbH, "DuraAct piezoelectric transducers," 1996-2017. [Online]. Available: https://www.piceramic.com/en/products/piezoceramicactuators/patch-transducers/. Accessed on: Jan. 16, 2017.

[11] P. Wierach, "Development of multifunctional materials systems with piezoceramic foils in the lead project adaptronics," in Proc. Adaptronic Congr., 2003.

[12] W. Hillger and A. Szewieczek, "Impact detection in a composite tail-boom structure with ultrasonic imaging- and guided waves techniques," in Proc. 10th Eur. Conf. Non-Destruct. Test., Moscow, 2010.

[13] D. Schmidt, D. Habas, and N. Dobmann, "Manufacturing of CFRP panels with integrated sensor network and contacting of the network," in Smart Intelligent Aircraft Structures. Cham, Switzerland: Springer, 2015, pp. 605-615.

[14] Z. S. Khodaei and M. H. Aliabadi, "A multi-level decision fusion strategy for condition based maintenance of composite structures," Materials, vol. 790, 2016, Art. no. E790.

[15] M. S. Salmanpour, Z. S. Khodaei, and M. H. Aliabadi, "Airborne transducer integrity under operational environment for structural health monitoring," Sensors, vol. 12, 2016, Art. no. 2110.

[16] M. Gall and B. Thielicke, "Life-span investigations of piezoceramic patch sensors and actuators," Proc. SPIE, Behav. Mech. Multifunct. Composite Mater, vol. 6526, 2007, Art. no. 65260P.

[17] T. Heber, M. Gude, and W. Hufenbach, "Production process adapted design of thermoplastic-compatible piezoceramic modules," Composites A, vol. 59, pp. 70-77, 2014.

[18] A. Gachagan, G. Hayward, and R. Banks, "A flexible piezoelectric transducer design for efficient generation and reception of ultrasonic Lamb waves," IEEE Trans. Ultrason., Ferroelectr., Freq. Control, vol. 52, no. 7, pp. 1175-1182, Jul. 2005

[19] M. Kobayashi, C. Jen, and D. Lévesque, "Flexible ultrasonic transducers," IEEE Trans. Ultrason., Ferroelectr., Freq. Control, vol. 53, no. 8, pp. 14781486, Aug. 2006.

[20] C. Yin, C. Chiu, W. Tsai, and J. Chen, "Flexible transducers for guided wave structural health monitoring of porous composite plates," in Proc. 19th World Conf. Non-Destruct. Test., Munich, 2016.

[21] C. R. Bowen, L. R. Bradley, D. P. Almond, and P. D. Wilcox, "Flexible piezoelectric transducer for ultrasonic inspection," Ultrasonics, vol. 48, pp. 367-375, 2008.

[22] C. Yin and W. Tsai, "Flexible ultrasonic transducers for transverse horizontal plate waves," in Proc. IEEE Int. Ultrason. Symp., Taipei, 2015, pp. $1-4$.

[23] P. S. Lowe, W. Duan, J. Kanfoud, and T.-H. Gan, "Structural health monitoring of above-ground storage tank floors by ultrasonic guided wave excitation on the tank wall," Sensors, vol. 17, no. 11, 2017, Art. no. E2542.

[24] A. G. Haig, R. M. Sanderson, P. J. Mudge, and W. Balachandran, "Macrofibre composite actuators for the transduction of Lamb and horizontal shear ultrasonic guided waves," Insight, Non-Destruct. Test. Condition Monit., vol. 55, no. 2, pp. 72-77, 2013.

[25] P. J. Mudge, A. M. Lank, and D. N. Alleyne, "A long range method of detection of corrosion under insulation in process pipework," J. JSNDI, vol. 46, pp. 314-319, 1997.

[26] P. S. Lowe, R. M. Sanderson, N. V. Boulgouris, A. G. Haig, and W. Balachandran, "Inspection of cylindrical structures using the first longitudinal guided wave mode in isolation for higher flaw sensitivity," IEEE Sens. J., vol. 16, no. 3, pp. 706-714, Feb. 2016.

[27] Abacus-SIMULIA, Abacus Version 6.13 User's Manual, Abacus, Waltham, MA, USA, 2013.

[28] Z. Sharif-Khodaei and M. H. Aliabadi, "Assessment of delay-and-sum algorithms for damage detection in aluminium and composite plates," Smart Mater. Struct., vol. 23, no. 7, 2014, Art. no. 07500.

[29] P. S. Lowe, R. Sanderson, N. V. Boulgouris, and T.-H. Gan, "Hybrid active focusing with adaptive dispersion for higher defect sensitivity in guided wave inspection of cylindrical structures," Nondestruct. Test. Eval., vol. 31, no. 3, pp. 219-234, 2015.

[30] B. Pavlakovic, M. Lowe, D. Alleyne, and P. Cawley, "Disperse: A general purpose program for creating dispersion curves," Rev. Prog. Quant. Nondestruct. Eval., vol. 16, pp. 185-192, 1997.

[31] G. Boivin, M. Viens, and P. Belanger, "Development of a low frequency shear horizontal piezoelectric transducer for the generation of plane $\mathrm{SH}$ waves," AIP Conf. Proc., vol. 1706, 2016, Art. no. 030019.

[32] PI Ceramics, "Piezoelectric ceramic components," PI Ceramics, Lederhose, Germany, 2007.
[33] D. N. Alleyne and M. J. S. Lowe, "The reflection of guided waves from circumferencial notches in the pipe," ASME J., vol. 65, pp. 635-641, 1998

[34] Polytec Ltd., "Retroreflective tape," 2017. [Online]. Available: http:/ www.polytec.com/uk/products/vibration-sensors/vibrometer-accessories/ surface-preparation/retroreflective-tape/. Accessed on: Jan. 18, 2017.

[35] Polytec Ltd., "PSV-500-3D scanning vibrometer," 2017. [Online]. Available: http://www.polytec.com/uk/products/vibration-sensors/scanningvibrometers/psv-500-3d-scanning-vibrometer/. Accessed on: Jan. 18, 2017.

[36] L. Mažeika, R. Kažys, R. Raišutis, and R. Šliteris, "Ultrasonic guided wave tomography for the inspection of the fuel tanks floor," in Proc. 4th Int. Conf. NDT, 2007.

[37] P. Wilcox, M. J. S. Lowe, and P. Cawley, "Mode and transducer selection for long range Lamb wave inspection," J. Intell. Mater. Syst. Struct. vol. 12 , no. 8, pp. 553-565, 2001.

[38] P. Belanger, "Feasibility of thickness mapping using ultrasonic guided waves," Ph.D. dissertation, Imperial College, London, U.K., 2009.

537 538

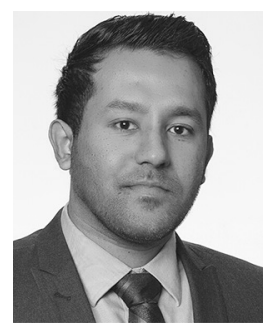

Premesh S. Lowe (S'13-M'16) received the Ph.D. degree from the Electrical and Compute Engineering Department, Brunel University London, Uxbridge, U.K., in 2016.

He commenced his career in the field of nondestructive testing by joining the Integrity Management Group of TWI Ltd., Cambridge, as a Research Engineer in 2012. Since 2015, he has been working as a Research Fellow with the Brunel Innovation Centre, Cambridge, U.K. His research is focused on finite element methods and signal processing on ultrasonic guided wave. He has authored or co-authored more than 20 peer-reviewed journals and conferences. His research interests include ultrasonic sensor development, sound energy focusing, and fouling removal using high power ultrasonics.

Dr. Lowe has been serving as a Reviewer for the IEEE Journals, NDT\&E, and Sensors Journal since 2014. He is an executive member of the IEEE UK\&I Section serving as the Chapter Officer since 2017.

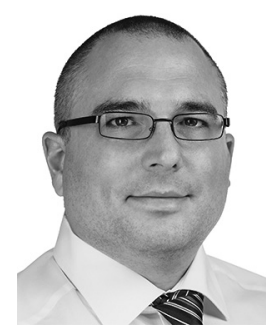

Timo Scholehwar received the Engineering degree in materials science from the Technical University Dresden, Dresden, Germany, in 2002, and the Ph.D. degree in 2011.

He started out as an Assistant Researcher with the Fraunhofer IKTS, Dresden, Germany, in 1997. In 2007, he became an Engineer for Piezo Components and Devices, PI Ceramic $\mathrm{GmbH}$ Lederhose, Germany, and a Senior Design Engineer for Piezo Materials and Components in 2017.

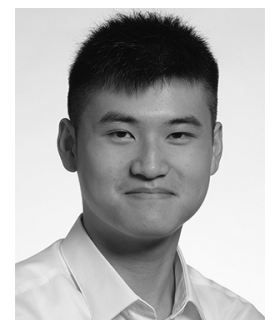

Jimmy Yau was born in Hong Kong. He is currently working toward the B.Eng. degree in mechanical engineering at the University of Surrey, Guildford, U.K.

In 2016, he joined the Brunel Innovation Centre, Uxbridge, U.K., as a Project Technical Assistant and he was involved in ultrasonic sensor and encapsulation design. His research interests include sensor development, numerical methods, and structural health monitoring.

\section{4} 555 556 


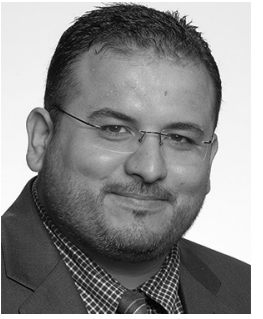

Jamil Kanfoud received the Master's degree in general engineering from l'Ecole Polytechnique de Tunisie, Tunisia, and the M.Phil. degree in numerical modeling from l'Université de Technologie de Compiègne, Compiègne, France.

$\mathrm{He}$ is a Technical Manager with the Brunel Innovation Centre, Uxbridge, U.K. Before joining Brunel University, he worked on modeling and optimizing a novel porous noise canceling solution for the Ariane $\mathrm{V}$ launcher fairings using BIOT-Allard theory. He has five years' academic experience, including two years heading the Electromechanical Department, ESPRIT. At TWI, he worked on active and passive vibration damping, and developed condition and structural health monitoring strategies and technologies for aerospace, renewable energy, and oil and gas using techniques ranging from vibration to acoustic emission. Since joining Brunel University, he has been working on developing research areas in nondestructive testing and condition monitoring including the development of novel sensing techniques (plenoptic cameras), the adoption of machine learning for inspection, and monitoring applications. He has a track record of proposing and managing collaborative projects and building strategic partnerships with industrial partners to increase technology readiness level of novel technologies in the field of structural integrity.

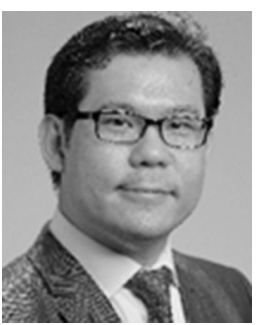

Tat-Hean Gan received the Graduate degree (first-class honors) in electrical and electronics engineering from the University of Nottingham, Nottingham, U.K., the M.Sc. degree (distinction) in advanced mechanical engineering in 1998 and the Ph.D. degree in engineering specializing in advanced ultrasonic imaging from the University of Warwick, Coventry, U.K., and the Executive MBA degree from the University of Birmingham, Birmingham, U.K., in 2006.

He has worked as an academic and in the industry for many years. He is currently a Professor with Brunel University London, Uxbridge, U.K., where he is also the Chair of acoustic waves technologies with the School of Engineering and Design. He is also an Associate Director of TWI Ltd., and the Technology Director of the National Structural Integrity Research Centre, the U.K.'s first industry-led postgraduate education and research center in structural integrity. $\mathrm{He}$ has authored or co-authored more than 100 papers and has contributed to several books in the field of nondestructive testing. His research interests include signal and image processing, sensor development, asset integrity management, and structural assessment.

Dr. Gan has received CEng, Eurlng, and IntPE (U.K.) status and is also a Fellow of the Institute of Engineering and Technology, British Institute of Non-Destructive Testing, International Society of Condition Monitoring, and International Society of Engineering Asset Management. He was a recipient of The Welding Institute Lidstone Award who is deemed to have made the most significant contribution to the advancement of welding technology.

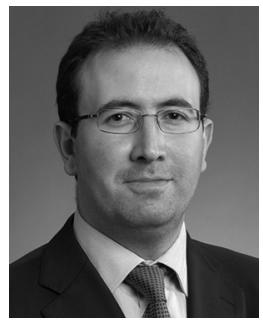

Cem Selcuk is the Business Development Con- 649 sultant and the Manager for Innovation Acceler- 650 ators with TWI Ltd., Great Abington, U.K. He was 651 the Manager and the Head of the Brunel Innova- 652 tion Centre. He is an active professional mem- 653 ber of the EPMA, APMI, IOM3 (FIMMM), and 654 The Welding Institute (FWeldl). He has been the 655 Chairman of the Particulate Engineering Com- 656 mittee, hence a member of the Materials Sci- 657 ence and Technology Board of the IOM3. He 658 has more than 190 citations to his publications 659 (more than 70) in peer-reviewed journals. He has presented at numerous 660 international conferences, authored book chapters and industrial project 661 reports, and contributed to white papers.

Mr. Selcuk has both served as a Referee and an Editor. He sits on 662 the editorial board of Powder Ms a Referee and an Editor. He sits on 663 


\section{Queries}

Q1. Author: Please note that Refs. [18] and [20] were identical, and Ref. [20] has been deleted. The subsequent references have been renumbered. Please check.

Q2. Author: Please provide the citation of Fig. 12 in the text.

Q3. Author: Please provide the page range in Refs. [7], [11], [12], [20], and [36].

Q4. Author: Please check Ref. [31] as set for correctness.

Q5. Author: Please provide the areas of study in which Premesh S. Lowe received the Ph.D. degree and Tat-Hean Gan received the Executive MBA degree.

Q6. Author: Please provide the area of study and the institution's name in which Timo Scholehwar received the Ph.D. degree.

Q7. Author: Please check the edits made to the educational details of Timo Scholehwar, and correct if necessary.

Q8. Author: Please provide the year in which Jamil Kanfoud received the Master's and M.Phil. degrees, and Tat-Hean Gan received the Graduate and Ph.D. degrees.

Q9. Author: Please provide the educational details of Cem Selcuk. 